$10-30-2017$

\title{
Predicting Dry-Season Flows with a Monthly Rainfall-Runoff Model: Performance for Gauged and Ungauged Catchments
}

Perrine Hamel

Stanford University

Andrew John Guswa

Smith College, aguswa@smith.edu

Jake Sahl

Stanford University

Lu Zhang

CSIRO Land and Water

Follow this and additional works at: https://scholarworks.smith.edu/egr_facpubs

Part of the Engineering Commons

\section{Recommended Citation}

Hamel, Perrine; Guswa, Andrew John; Sahl, Jake; and Zhang, Lu, "Predicting Dry-Season Flows with a Monthly Rainfall-Runoff Model: Performance for Gauged and Ungauged Catchments" (2017). Engineering: Faculty Publications, Smith College, Northampton, MA.

https://scholarworks.smith.edu/egr_facpubs/16 


\section{Predicting dry-season flows with a monthly rainfall-runoff model: performance for gauged and ungauged catchments}

\begin{tabular}{|r|l|}
\hline Journal: & Hydrological Processes \\
\hline Manuscript ID & HYP-16-0717.R2 \\
\hline Diley - Manuscript type: & Research Article \\
\hline Complete List of Authors: & $\begin{array}{l}\text { Hamel, Perrine; Stanford University Woods Institute for the Environment, } \\
\text { Natural Capital Project } \\
\text { Guswa, Andrew; Smith College, Picker Engineering Program } \\
\text { Sahl, Jake; Stanford University Woods Institute for the Environment, } \\
\text { Natural Capital Project } \\
\text { Zhang, Lu; CSIRO Land and Water, Christian Laboratory }\end{array}$ \\
\hline Keywords: & $\begin{array}{l}\text { baseflow, land-use change, climate change, DWBM, prediction in ungauged } \\
\text { basins }\end{array}$ \\
\hline & \\
\hline
\end{tabular}

SCHOLARONE ${ }^{\text {Im }}$

Manuscripts 
1 Predicting dry-season flows with a monthly rainfall-runoff model:

2 performance for gauged and ungauged catchments

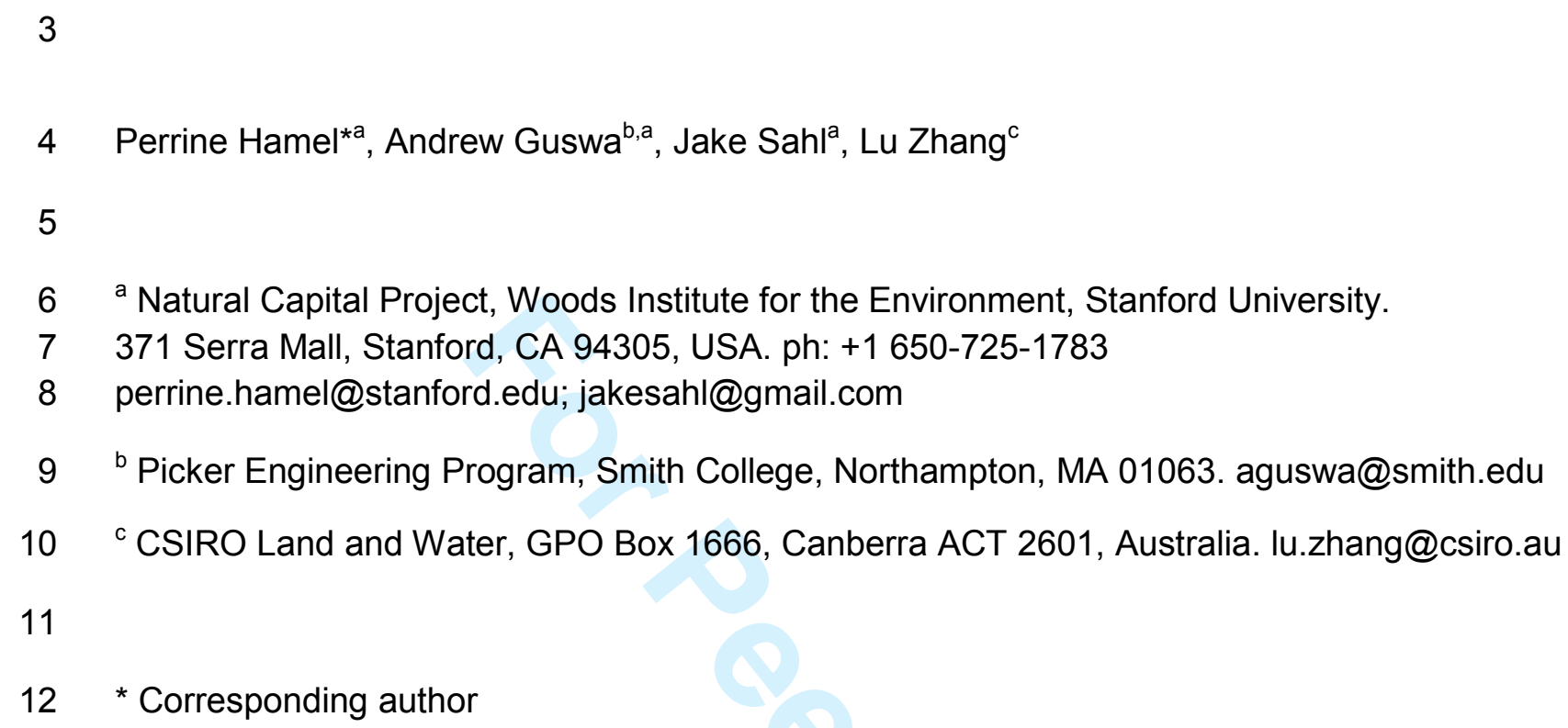




\section{Abstract}

14 Hydrologic models are useful to understand the effects of climate and land-use changes on dry15 season flows. In practice, there is often a trade-off between simplicity and accuracy, especially 16 when resources for catchment management are scarce. Here, we evaluated the performance of 17 a monthly rainfall-runoff model (dynamic water balance model, DWBM) for dry-season flow 18 prediction under climate and land-use change. Using different methods with decreasing 19 amounts of catchment information to set the four model parameters, we predicted dry-season 20 flow for 89 Australian catchments, and verified model performance with an independent dataset 21 of 641 catchments in the United States. For the Australian catchments, model performance 22 without catchment information (other than climate forcing) was fair; it increased significantly as

23 the information to infer the four model parameters increased. Regressions to infer model

24 parameters from catchment characteristics did not hold for catchments in the United States, 25 meaning that a new calibration effort was needed to increase model performance there.

26 Recognizing the interest in relative change for practical applications, we also examined how 27 DWBM could be used to simulate a change in dry-season flow following land-use change. We 28 compared results with and without calibration data, and showed that predictions of changes in 29 dry-season flow were robust with respect to uncertainty in model parameters. Our analyses 30 confirm that climate is a strong driver of dry-season flow and that parsimonious models such as 31 DWBM have useful management applications: predicting seasonal flow under various climate 32 forcings when calibration data are available, and providing estimates of the relative effect of 33 land-use on seasonal flow for ungauged catchments.

34 Keywords: baseflow; land-use change; climate change; DWBM; prediction for ungauged basins 35 


\section{Introduction}

37 With increasing pressure on water resources globally, managers of water resources need to 38 understand how streamflows - in particular, dry-season flows - respond to changes in land use 39 and climate. Applications vary broadly: at the global scale, hydrologists aim to better predict the 40 effect of agricultural expansion on water resources to avoid additional pressure in water-scarce 41 regions (Brauman et al., 2016). At the regional scale, water resources assessments are needed 42 to explore and implement efficient water-allocation plans (Kirby et al., 2014). For example, the 43 development of hydropower production facilities in Africa or South-East Asia requires the 44 prediction of annual and monthly flows (Vogl et al., 2016). In Latin America, the development of 45 investment in watershed services programs requires stakeholders to estimate the effect of land 46 management on hydrological services (Bremer et al., 2016; Guswa et al. 2014).

47 A number of knowledge gaps hinder the development of decision-aid tools for water resources 48 management. First, the effects of environmental changes on baseflow remain uncertain 49 (Andréassian, 2004; Brown et al., 2013, 2005; Price, 2011). Here, we define baseflow as

50 "streamflow fed from deep subsurface and delayed shallow subsurface storage between 51 precipitation and/or snowmelt events" (Price, 2011). Baseflow depends on many factors: climate 52 (magnitude and seasonality of precipitation and evapotranspiration), topography, geology, and 53 land use and land cover - with vegetation type and age as key subfactors (Brutsaert, 2008; Gao 54 et al., 2015; Zhang et al., 2014). In addition, the relative importance of these factors vary in time, 55 at the event and seasonal time scales (Devito et al., 2005; Jencso and McGlynn, 2011), making 56 it difficult to characterize in a given location. Second, relatedly, hydrologic models are limited in 57 their ability to estimate dry-season flow: lumped models tend to oversimplify the complexity of 58 hydrological processes, which casts doubt on their capacity to predict the effect of land use or 59 climate change. Complex models have high-data needs, require calibration, and often show 
60 high uncertainty for predictions outside of the calibration conditions (in particular under land-use

61 change) (Mclntyre et al., 2014; Smith et al., 2004).

62 Recognizing and seeking to fill these knowledge gaps is important, and taking stock of current

63 knowledge and its usefulness for practical applications is of equal priority for management. By

64 identifying questions that are of interest for water-resources management, hydrologists can

65 better understand where research gaps need to be filled. Typically, answering landscape

66 management questions requires an understanding of: i) the absolute magnitude of the change

67 in dry-season flow following land-use or climate change; ii) the relative difference in dry-season

68 flows among various land uses or management scenarios (e.g. afforestation, deforestation,

69 water abstraction for domestic or agricultural use); and iii) the spatial distribution of contributions

70 to baseflow (i.e. whether some part of the landscapes provide more baseflow than others)

71 (Guswa et al., 2014).

72 This paper explores the first two questions by analyzing how a simple monthly rainfall-runoff

73 model can capture major drivers of dry-season flow. Our aim is to quantify predictive uncertainty

74 in dry-season flow across a wide range of climate and catchment characteristics, and to assess

75 how this uncertainty changes as catchment information is introduced. In an era of increasingly

76 available data, in particular global daily precipitation data (Gehne et al., 2016), our work at the

77 monthly time step is justified by the parsimony of models operating at this time scale (Mouehli et

78 al., 2006). This characteristic facilitates regionalization and work in ungauged basins (Perrin et

79 al., 2001), as well as any analysis that does not necessitate short time-scale representation of

80 the flow regime: e.g., optimization approaches for reservoir operation or irrigation schemes

81 (Hughes, 2004; Kirby et al., 2014), or drought assessment (Smakhtin and Hughes, 2007). In

82 both circumstances, quantifying the uncertainty of uncalibrated models is important to produce

83 credible information for management, potentially overcoming the need for more sophisticated

84 models (Guswa et al., 2014). 
85 Here, we used DWBM (dynamic water balance model) with a monthly time step (Zhang et al. 86 2008). The model has four parameters with physical interpretation and was shown to explain 87 flow variations for a large number of catchments in Australia (Zhang et al., 2016, 2008). After 88 describing the model and how climate influences its behavior, we examine the correlations 89 between catchment characteristics and calibrated model parameters. We examine how model 90 parameters are correlated with physical characteristics, and show that model performance for 91 dry-season flow prediction decreases sharply when catchment information is reduced. We also 92 examine predicted change in dry-season flow following a simulated land-use change, showing 93 that catchment information does not influence the general direction and magnitude of these 94 predictions. We discuss the implications of this work in Section 5, with a focus on the 95 importance of climate change relative to land-use change; we suggest that parsimonious 96 monthly models have practical utility when calibration data are available and when the main 97 objective of the study is to explore the relative effect of land use or climate change on seasonal 98 flow.

\section{A simple monthly water balance model for environmental change}

\section{$101 \quad 2.1$ Overview and comparison with other models}

102 The model used in this study, DWBM, is a four-parameter lumped catchment model that 103 partitions monthly precipitation into evapotranspiration and runoff (see full description in section 104 2.2). DWBM was developed by Zhang et al. (2008) with the aim to extend the Budyko theory, or 105 "limits" concept, to sub-annual timescales (Budyko, 1961; Hamel and Guswa, 2015). The model 106 also has a five-parameter version (Wang et al., 2011) but for the purpose of this study, we 107 employ the more parsimonious version, which has been verified on a subset of $>200$ 108 catchments in Australia (Zhang et al. 2008). 
109 DWBM is similar to a number of parsimonious lumped models, including abcd and G2M

110 (Mouelhi et al., 2006), which represent a catchment with one or two stores of water that

111 influence the basin-scale partitioning of precipitation into evapotranspiration and runoff. These

112 models continue to receive attention from the hydrologic community given the uncertainty

113 associated with complex models: for example, in their study of 429 catchments around the

114 world, Perrin et al. (2001) showed that models with a low number of parameters $(<5)$ achieved a

115 performance comparable to more complex models, and recommended their use due to the ease

116 of assessing parameter uncertainty with such models. As described later, DWBM has the

117 advantage of using parameters with physical meaning, which facilitates interpretation of results

118 and inferring the effects of landscape modification. In general, we note that the selection of

119 DWBM does not impact the scope and ideas implemented in this study. Similar analyses could

120 be conducted with alternative models, and we suggest that a number of findings would hold: the

121 "equifinality of model structures", as defined by Perrin et al. (2001), suggest that most

122 parsimonious models would yield similar results.

$123 \quad 2.2$ Model description

124 - Model equations

125 The DWBM model operates with two stores of water for a catchment - the vadose zone and

126 groundwater. Monthly precipitation is partitioned among direct runoff, evapotranspiration,

127 storage in the vadose zone, and recharge to groundwater; monthly streamflow is a combination

128 of direct runoff and baseflow supplied by the groundwater store. The following section describes

129 the main equations but the reader is referred to the full description of model development for

130 additional details (Zhang et al. 2008).

131 For each month, the model first partitions precipitation into catchment wetting and direct runoff.

132 Catchment wetting, $\mathrm{X}$, for a month, $\mathrm{m}$, is bounded by both a supply limit $\left(\mathrm{P}_{\mathrm{m}}\right.$, the precipitation 
2

133 arriving in that month) and a demand limit, $\mathrm{X}_{0}$. Mathematically, this "limit" concept is captured by 134 a bi-asymptotic function (Figure 1), and catchment wetting is computed as:

$$
X(m)=P(m) F\left(\frac{X_{0}}{P(m)}, \alpha_{1}\right)
$$

135

136 Where $\mathrm{F}$ is the bi-asymptotic function, defined as:

137

$$
F(x, \alpha)=1+x-\left(1+x^{\frac{1}{1-\alpha}}\right)^{1-\alpha}
$$

138

$139 \alpha_{1}$ is the retention efficiency, which determines how close $\mathrm{X}$ is to the supply and demand limits;

140 the "demand limit" $X_{0}$ is calculated as the sum of available storage capacity and

141 evapotranspiration demand, (here called potential evapotranspiration, PET):

$$
X_{0}(m)=S_{\max }-S(m-1)+\operatorname{PET}(m)
$$

142

143 where $S_{\max }$ is the maximum catchment storage capacity and $\mathrm{S}$ the catchment storage value at a 144 given time step.

\section{5 [FIGURE 1]}

146

147 For each month, $\mathrm{X}$ is used to compute an intermediate variable, available water, W:

$$
W(m)=X(m)+S(m-1)
$$


149 as well as the direct flow, $Q_{d}$, i.e. water not retained in the catchment that quickly becomes

150 streamflow:

$$
Q_{d}(m)=P(m)-X(m)
$$

151

152 The available water, $\mathrm{W}$, is partitioned among evapotranspiration, storage and recharge. To do

153 so, the model computes the evapotranspiration opportunity, Y, i.e. the proportion of available

154 water that does not percolate below the root zone and become recharge. The supply limit for $Y$

155 is the available water, while the demand limit is the sum of potential evapotranspiration and

156 storage; therefore

$$
Y(m)=W(m) \times F\left(\frac{\left.P E T(m)+S_{\max }\right)}{W(m)}, \alpha_{2}\right)
$$

158 where $\alpha_{2}$ is the evapotranspiration efficiency, which determines how close $Y$ is to the supply and 159 demand limits (Figure 1).

160 Monthly evapotranspiration, ET, is bounded by the available water and energy demand (PET). It 161 is assumed that ET follows the same function as $Y$, i.e. that the evapotranspiration efficiency $\alpha_{2}$ 162 also determines how close ET is to the evapotranspiration demand:

$$
E T(m)=W(m) \times F\left(\frac{P E T(m)}{W(m)}, \alpha_{2}\right)
$$

164 Recharge can then be calculated as the difference between available water and

165 evapotranspiration opportunity: 


$$
R(m)=W(m)-Y(m)
$$

166

167 and storage is the difference between evapotranspiration opportunity and actual

168 evapotranspiration:

$$
S(m)=Y(m)-E T(m)
$$

169

[9]

170 Finally, monthly baseflow is calculated as:

$$
Q_{b}(m)=d \cdot G(m-1)
$$

172 where $d$ is the groundwater store time constant, characterizing the groundwater drainage rate,

173 and $\mathrm{G}$ is groundwater storage, updated monthly as:

$$
G(m)=G(m-1)-Q_{b}(m)+R(m)
$$

175 Total streamflow is calculated as the sum of direct flow and baseflow.

177 - Interpretation in terms of environmental change

178 Given our focus on environmental change, we elaborate here on how climate and land-use 179 changes can be represented by the model. Table 1 summarizes the expected relation between 180 the four parameters and physical catchment characteristics. We suggest that changes in land181 use and land-cover will likely affect $S_{\max }, \alpha_{1}$ and $\alpha_{2}$ : changes to root depth and soil properties 
182 may alter the partitioning between direct runoff and soil storage, along with the partitioning of 183 soil water between groundwater recharge and evapotranspiration. The parameter d affects only 184 the monthly timing of baseflow, and we suggest that $d$ is primarily a function of geology and not 185 significantly influenced by land use or climate changes. (At the daily time scale, the dynamic 186 storage theory suggests that it also depends on antecedent conditions, i.e., on land use and 187 climate features, cf. Kirchner, 2009).

188 Seasonal changes in precipitation and potential evapotranspiration will be captured by the 189 climate forcing variables. Changes in the intensity of individual precipitation events, a 190 characteristic not described by the monthly total, will likely affect $\alpha_{1}$, since higher intensity events 191 may result in more direct runoff. Indirect climate change effects may also affect soil and 192 vegetation properties, suggesting that $\alpha_{2}$ and potentially $S_{\max }$ may be affected by climate change 193 (Table 1).

194 [TABLE 1]

195 


\section{Methods}

\section{$197 \quad 3.1$ Overview}

198 Our aim is to quantify the uncertainty in minimum flow predictions across a wide range of 199 climate and catchment characteristics, and to understand how this uncertainty evolves as 200 catchment information is introduced. Our analyses rely on two metrics, minimum monthly flow $201\left(Q_{\text {min }}\right)$ and total flow $\left(Q_{\text {tot }}\right)$, computed as the minimum average monthly flow and average annual 202 flow, respectively, across the period of record. Here, minimum monthly flow is used to represent 203 dry-season flow, thereby using a flow-based definition of the dry season.

204 We first conduct a brief sensitivity analysis to illustrate the model response to climate forcing.

205 Building on previous work in Australia (Zhang et al. 2008), we compare observed minimum

206 monthly flows for 89 catchments to predictions from four versions of DWBM: one with

207 parameters obtained from calibration, two where parameters are determined via regression on

208 catchment characteristics, and one with no variation in model parameters among catchments

209 (i.e., the only variation in models among the basins is the climate forcing). We then use the 210 DWBM to predict low flows in 641 catchments in the United States. To assess the universality of 211 the regression models developed for the Australian catchments, we employ the same 212 regression models to determine model parameters for the US basins. We also evaluate the 213 performance of the DWBM with fixed parameters across the US catchments and with an 214 independent calibration. Finally, we explore the use of DWBM to assess the potential effect of 215 land-use change on dry-season flows for ungauged basins. In doing so, we evaluate whether 216 the model can predict land-use change effects in relative terms, even if the absolute magnitude 217 of minimum flows is not well predicted. 
2193.2 Sensitivity analysis: relative importance of catchment characteristics on annual and 220 dry-season flow

221 To demonstrate model behavior, we present the sensitivity of our two variables of interest, 222 minimum monthly flow and total flow, to both climate forcing and model parameters (which are 223 proxies for catchment characteristics). We present three distinct climates, subtropical-dry 224 summer, tropical-dry winter, and humid continental. Details of the analyses and in-depth 225 discussion of the hydrological processes driving the results are presented in Appendix 1.

\section{$226 \quad 3.3 \quad$ Parameter selection and model performance (Australian dataset)}

227 Given the physical interpretation of DWBM parameters (Section 2.2), we expect their values to 228 be correlated with measurable characteristics of a catchment. We tested this hypothesis on a 229 dataset of 89 catchments in Australia for which the DWBM model was calibrated using four 230 objective functions related to low flows, high flows, time shift, and total mass balance (Zhang et 231 al. 2008). Catchment areas vary between 50 and $2000 \mathrm{~km}^{2}$ and are located across a large 232 range of climate zones (Figure 2a). We examined twelve relevant and readily available 233 catchment characteristics as explanatory variables for the regression, including information on 234 climate, soil, topography, and land use (Table 2). Data sources for catchment streamflow time 235 series and characteristics are described by Shao et al. (2012). Each catchment had at least 10 236 years of climate and streamflow data, which we used to run the model and obtain a time series 237 of monthly modeled streamflow. For both observed and modeled time series, we computed the 238 average monthly flows and extracted the minimum and total annual flow to obtain the values of $239 Q_{\min }$ and $Q_{\text {tot }}$ for each catchment. After conducting a simple backward stepwise linear regression 240 model that had low predictive power (see Table 1), we developed two regression approaches 241 described below. 


\section{3 [FIGURE 2]}

244 [TABLE 2]

- Regression with the full set of variables (regression trees)

247 We built regression trees to explore how much variability in parameter values could be

248 explained by the complete set of catchment characteristics given in Table 2. Regression trees

249 were selected for their high explanatory power, when compared with multiple linear regressions 250 and a multivariate adaptive regression spline (MARS) model (Shao et al., 2012). The analyses 251 were performed with the 'rpart' package in the R environment. We tested simple and pruned 252 trees and finally selected a random forest method, using the 'randomForest' ${ }^{2}$ package in $\mathrm{R}$, 253 which gave the best performance. This method consists in creating thousands of unique 254 regression trees for the same dataset, using a random sampling of variables to create each tree 255 (Breiman, 2001). Each of these trees is used to predict the dependent variable, and the mean 256 prediction from the entire forest is the output. After "growing" a forest for each parameter, we 257 perform a 'leave-one-out' cross-validation, i.e. building a random forest using every observation 258 (the parameter values) except one, then using the model to predict the observation that was left 259 out. The process is repeated until the model has predicted every observation in the dataset, 260 after which the average prediction error is calculated.

261 - Multiple linear regression on a reduced set of variables

262 To assess the model performance in a situation with reduced data availability, we test a simple 263 linear regression model that relies on direct physical interpretation of parameters. Specifically, 264 we tested the correlation between each parameter and the catchment characteristics

\footnotetext{
${ }^{1}$ https://cran.r-project.org/web/packages/rpart/index.html

${ }^{2}$ https://cran.r-project.org/web/packages/randomForest/index.html
} 
265 considered as the best proxies for the parameter. The following paragraphs explain the rationale 266 behind the selection of catchment characteristics for this simplified approach.

$267 \alpha_{1}$, the retention capacity, is closely related to the curve number (CN) used in the SCS-method 268 (NRCS-USDA, 2004). This empirical value captures the ability of a catchment to retain water in 269 the soil layer instead of producing direct runoff. Therefore, we tested the correlation between $\alpha_{1}$ 270 and $\mathrm{CN}$ values for each catchment. $\mathrm{CN}$ values were calculated as the weighted average of $\mathrm{CN}$

271 for forest and grass land covers. Soil hydrologic groups were estimated from the HiHydroSoil 272 dataset (Boer, 2015)

$273 \quad \alpha_{2}$ is related to soil drainage and rain event frequency. Therefore, we used the subsoil hydraulic 274 conductivity and average storm depth as explanatory variables for $\alpha_{2}$.

$275 S_{\max }$ is related to the product of soil depth and saturated water content. Because the soil dataset 276 we used did not show any variability in soil depths (all depths $>2400 \mathrm{~mm}$ ), we only used

277 saturated water content in the regression.

278 d is related to hydraulic conductivity of deep layers. We used the subsoil hydraulic conductivity 279 as the only explanatory variable.

$280 \quad$ - Mean parameters

281 We also tested a case for which no catchment-specific information is used to estimate the 282 parameters. For this, we used the mean values of the calibrated parameters across all 283 Australian catchments. For these analyses, only climate forcing varies among the models from 284 one catchment to the next.

285 - Model performance 
286 We ran the DWBM model three times for each Australian catchment with the parameter sets 287 described above, i.e. determined by the full regression model, the reduced regression model, 288 and the mean value. We compared the minimum flow and total flow predicted with each 289 parameterization, including the parameter set obtained by calibration, with the minimum flow 290 and total flow obtained from observed time series.

\section{$291 \quad 3.4 \quad$ Model verification (US dataset)}

292 We tested the performance of the modified DWBM, i.e. applied with the regressed set of 293 parameters, outside Australia. To compare the model performance when calibration data are 294 available, we also calibrated the model for the verification dataset. For this calibration, we used 295 a single objective function, the Nash-Sutcliffe efficiency for log-transformed flow, consistent with 296 our focus on low flows.

297 Our dataset of US catchments was developed by Newman et al. (2015), comprising 671 298 catchments (although we discarded 30 catchments for quality assurance reasons, see Appendix 299 B). Similar to the Australian dataset, the catchments range in size (1 to $\left.25,800 \mathrm{~km}^{2}\right)$ and 300 hydroclimatic conditions (Figure 2b). To run DWBM on the US dataset, we summed 301 precipitation data at the monthly time step and computed monthly potential evapotranspiration 302 from monthly temperature data, using the modified Hargreaves method (Eq. 5 from Droogers et 303 al., 2002). $Q_{\min }$ and $Q_{\text {tot }}$ and model performance metrics for the US dataset were calculated with 304 the method described above for the Australian dataset, i.e. we compared the $Q_{\min }$ and $Q_{\text {tot }}$ 305 predictions based on the three alternative parameterizations with observations. To further 306 explore the variability in model performance, we grouped results by region, according to the 307 USGS HUC 02 classification. 


\subsection{Variation of model performance with catchment characteristics}

We examined the correlation between model errors and catchment characteristics to identify the

310 conditions under which the model performs best. Specifically, we computed $r^{2}$ and $p$-values

311 between errors in $Q_{\min }$ and $Q_{\text {tot }}$ obtained from each model parameterization, on one hand, and

312 all catchment characteristics listed in Table 2, on the other hand.

\section{$313 \quad 3.6$ Simulated effect of land-use change in ungauged basins}

314 The parameters for the DWBM each incorporate the effects of a host of climate, landscape, and 315 geologic factors, some of which are measurable and others which are not. Thus, detecting a 316 land-use signal in the parameters when moving from one catchment to another may be 317 challenging, as the effects of land-use alone may be lost amid the noise and other differences 318 between the catchments. Nonetheless, we were interested in assessing model predictions of 319 land-use change, in relative terms, within a particular catchment.

320 As noted in Table 1, land-use change presumably affects $\alpha_{1}$ and $\alpha_{2}$. Over the longer term, land321 use change may affect soil properties (i.e. $S_{\max }$ ), but this effect is arguably weaker and ignored 322 in these analyses. It is possible that the flow response to a change in $\alpha_{1}$ and $\alpha_{2}$, representing 323 land-use change, may be a function of their original values. To test this hypothesis, we 324 investigated the effect of simultaneous $10 \%$ and $20 \%$ changes in $\alpha_{1}$ and $\alpha_{2}$ for each Australian 325 catchment, for both the calibrated dataset (for which the $\alpha_{1}$ and $\alpha_{2}$ parameters vary among the 326 basins) and the mean-value dataset (which all share the same parameter values). If the 327 changes in $Q_{\min }$ that result from changes in $\alpha_{1}$ and $\alpha_{2}$ are comparable between the two models 328 (calibrated and mean value), we can conclude that the effects of afforestation/deforestation on 329 minimum flows are independent of the original parameter values. Thus, in an ungauged basin 330 for which little information is available, the mean-value model could be used to predict the 331 effects of land-use change. The values of relative change (10 and $20 \%)$ were based on the 
332 maximum change in parameter values predicted by the random forest model: $\alpha_{1}$ and $\alpha_{2}$

333 increased by a maximum of $6 \%$ and $13 \%$, respectively, when forest cover was increased by $33466 \%$ (for catchments with a cover $<34 \%$ ).

335

\section{Results}

\section{$337 \quad 4.1 \quad$ Sensitivity analysis}

338 In general, the model shows greater sensitivity to parameters for the subtropical and tropical 339 climates (Figure 3). In the humid climate, catchment properties have a lower impact on 340 minimum flows, since evapotranspiration is primarily energy-limited and changes in catchment 341 water storage have little effect on hydrologic partitioning. In subtropical dry-summer and dry342 winter climates, a small decrease in $\alpha_{1}$ or $\alpha_{2}$ may lead to a sharp relative increase in $Q_{\min }$, due to 343 increases in the small amounts of surface runoff during dry months. Conversely, as $\alpha_{1}$ or $\alpha_{2}$ 344 increase, $Q_{\min }$ generally decreases as water retained in the soil store is more likely to be 345 evapotranspired.

346 Based on the above analyses, predictions of minimum flows will be minimally impacted by 347 changes in parameter values when: climate is humid with low seasonality in precipitation, i.e. 348 variability in evaporative demand is the main driver of minimum flows; and when catchment 349 properties correspond to "insensitive" ranges for model parameters. For example, Figure 3 350 shows that minimum flows are not sensitive to low values of $\alpha_{1}$ for the tropical dry-winter 351 climate. In such climate, minimum flows in catchments with low retention capacity (e.g. with 352 clayey or compacted soils) are unlikely to be affected by land use change.

354 [FIGURE 3] 


\section{$357 \quad 4.2$ Regression models for DWBM's parameters}

358 The results from the random forest model are summarized in Table 3, showing that $r^{2}$ was high

359 for all parameters. The mean predictive errors obtained with the random forest method for $\alpha_{1}$,

$360 \alpha_{2}, S_{\max }$, and $d$ are reported in Table 3 and represent $45 \%, 39 \%, 40 \%$, and $42 \%$ of their

361 respective mean value (Table 3). To gauge the impact of errors of this magnitude on model

362 outputs, we plotted these error ranges on the sensitivity analyses graphs (Figure 3): the effect of 363 parameter errors was relatively low for $Q_{\text {tot }}$, but for the semi-arid and tropical climates, errors in $364 \alpha_{2}$ and d may affect $Q_{\min }$ significantly (>50\% error). In addition, the reduced regression model 365 showed much less explanatory power (Table 3): the reduced set of variables explaining less 366 than $20 \%$ of the variance in the calibrated parameter set.

367 Of the thirteen variables in Table 2, the curve number $\mathrm{CN}$ ranked as the most important variable 368 for $\alpha_{1}$ and forest cover as the fourth most important variable. Here, importance is computed as 369 follows (see details in footnote 2 above): the mean square error is calculated on the out-of-bag 370 portion of the dataset, and again on the dataset with permuted variable; then, the average 371 difference in mean square error over all trees is computed, and normalized by the standard 372 deviation of the differences. For $\alpha_{2}$, the four most important variables were all climate-related 373 (Peomonths, Aridity, Precipitation,CVP).

375 [TABLE 3] 


\section{$377 \quad 4.3$ Model performance (Australian dataset)}

378 Figure 4 and Table 4 illustrate the model performance for $Q_{\min }$ for the Australian dataset.

379 Comparison of results from the calibrated models to the observed minimum flows yielded a root380 mean-square error (RMSE) of $2.37 \mathrm{~mm} / \mathrm{mo}$ (i.e. about $50 \%$ of the average minimum flow, 4.63 $381 \mathrm{~mm} / \mathrm{mo}$ ). The model with parameters obtained from the full regression ("full regression model" 382 hereafter) yielded good results for $Q_{\min }$, with a RMSE of $2.32 \mathrm{~mm} / \mathrm{mo}$ (Table 4 ) - similar to the 383 performance of the calibrated models. Model performance was lower when using the reduced 384 regression or the mean values for parameters, although these models still explained a large 385 proportion of the variance in $Q_{\min }(>53 \%)$.

386 The four models predicted total flows well, with $r^{2}$ values $>0.87$ (Table 4). The lowest RMSE for 387 total flows was obtained by the model with calibrated values (RMSE=42.4 $\mathrm{mm} /$ year), and the 388 highest was obtained by the model with mean values.

390 [FIGURE 4]

$391 \quad$ [TABLE 4]

\subsection{Model verification (US dataset)}

394 With the parameters obtained from the full regression, the performance of DWBM for minimum 395 flows was lower in the US (Table 4). The model explained $92 \%$ of the variance in $Q_{\text {tot, }}$ but only 396 between 51 and $55 \%$ of the variance in $Q_{\min }$ (Table 4, Figure 5). As information was introduced 397 by the full regression and reduced regression, there was no improvement in model performance 398 over the mean-value model (RMSE in $\mathrm{Q}_{\min }$ for the simplified regression was lower than the full 399 regression but the difference was not statistically significant, based on a Kolmogorov-Smirnov 
400 test). However, calibration of the models based on log-transformed Nash-Sutcliffe efficiency

401 resulted in much higher performance -with $88 \%$ of the variance in $\mathrm{Q}_{\min }$ explained, similar to the

402 Australian dataset. The calibrated value ranges were slightly broader than those of the

403 Australian dataset, [0.36;0.99], [0.16;0.94], [0.10; 1], and [32; 500], respectively, for $\alpha_{1}, \alpha_{2}$,

404 Smax, and d (Australian ranges are reported in Table 3).

405

406 [FIGURE 5]

407

4084.5 Correlation between errors in $Q_{\min }$ and catchment characteristics

409 When using the calibrated parameters for the Australian catchments, we found significant

410 correlations $(p<0.01)$ between the relative error in minimum flow and three catchment

411 characteristics: aridity, precipitation, and PAWHC (all negative correlations). Errors in total flow

412 also showed strong correlations with catchment characteristics, in particular with climate

413 variables, and soil properties.

414 When using model predictions from the full regression model, errors in minimum flow showed

415 significant correlation only with the aridity index, and errors in total flow with precipitation and

416 the aridity index. No correlation was found for any catchment characteristics for predictions

417 obtained with the reduced regression or mean models.

418 We found no significant correlation between catchment characteristics and relative errors in

419 minimum flows for the US catchments, for any parameter set. However, relative errors in total

420 flows were correlated with a number of catchment characteristics (all variables in Table 2 except

$421 \mathrm{CN}$ and the relief ratio), and with two parameters (positive correlation, for both $\alpha_{2}$, and d). 
422 To explore the regional variation in model performance in the US, we separated the catchments 423 by region, using the USGS HUC 2 classification (Figure 2). Across these more homogenous 424 units, the calibrated model performance varied without significant pattern. However, the 425 improvement upon regression and mean-value models is more appreciable for HUCs with 426 higher values, which comprise more arid regions, a finding that seems consistent with the higher 427 performance of the model in arid catchments in Australia.

\subsection{Simulated effect of land-use change in ungauged basins}

430 Figure 6a represents the relative change in $Q_{\min }$ following $10 \%$ and $20 \%$ changes (both positive 431 and negative) in $\alpha_{1}$ and $\alpha_{2}$. All values in the bottom-left quadrant represent an increase in $\alpha_{1}$ and $432 \alpha_{2}$, while all values in the top-right quadrant represent a decrease in the two parameters. The 433 direction of the change is consistent between the calibrated and mean datasets. The difference 434 in $Q_{\min }$ predicted by the models was small for the $10 \%$ change in parameter (RMSE of 0.36 ). For 435 the $20 \%$ change, the high RMSE (1.2) was largely driven by the negative change in parameter 436 values (i.e. circles in the top-right quadrant in Figure 6a). Of note, these high relative changes 437 correspond to low absolute changes: the RMSE for the absolute change in $Q_{\min }$ resulting from a $43820 \%$ change (both positive and negative) in parameters is $1.5 \mathrm{~mm}$.

439 The results for total flow (Figure 6b) showed even smaller differences between the two models, 440 indicating that medium to high flows were less affected, in relative terms, by the change in 441 parameter values. RMSE were 0.15 and 0.37 , respectively, for the $10 \%$ and $20 \%$ change in 442 parameter values. 


\section{Discussion and implications for predicting the effects of environmental}

\section{change}

448 The main objective of this paper is to assess the utility of a monthly, lumped hydrologic model

449 for predicting dry-season flows with varying degrees of information availability. As a rainfall-

450 runoff model governed by four parameters with physical meaning, DWBM has the potential to

451 be used for climate and land-use change scenarios analyses and inform landscape

452 management. The sensitivity analyses indicated that the importance of each parameter

453 depends on climate: for example, a larger storage capacity $S_{\max }$ will generally be needed in

454 highly seasonal climate to sustain baseflow during the dry season. The moderate sensitivity in a 455 number of environmental contexts (i.e. parameter sets) suggests that climate is the main driver 456 of seasonal flow, a fact that has been observed by many others (Devito et al., 2005; Jencso and 457 McGlynn, 2011). In practice, this means that a rough estimate of these parameters may be

458 sufficient to predict monthly flows with acceptable levels of certainty, as suggested by our 459 analyses on Australian and US catchments.

\section{$460 \quad 5.1$ Model performance for absolute predictions of dry-season flow}

461 The model performance, measured by $r^{2}$, in Australia was relatively high for both $Q_{\min }$ and $Q_{\text {tot }}$ 462 predictions (Figure 4). RMSE for $Q_{\min }$ ranged from $2.4 \mathrm{~mm} / \mathrm{mo}$ to $4.0 \mathrm{~mm} / \mathrm{mo}$, depending on the 463 model parameterization. Adding catchment information, i.e. moving from uniform parameters for 464 all catchments, to regressed parameter values, to streamflow time series for calibration, 465 generally improved model performance (measured by RMSE). The performance of the full 466 regression model was actually as good as the calibrated model, probably due to the large 467 number of explanatory variables and the high explanatory power of the regression (Table 3).

468 The poorer performance of the reduced regression could be due to two factors: poor selection of 
469 model variables and over-fitting of the random forest full regression model. The stepwise 470 backward regression conducted in preliminary analyses confirmed that our selected variables 471 are among the best predictors, but that no single variable explained the variance significantly. 472 This suggests that the full regression model was probably over-fitted (12 variables for 89 473 observations), and therefore less likely to transfer outside the initial sample, for the US 474 catchments.

475 For the verification dataset with US catchments, the performance of DWBM with parameters 476 derived from the full regression was much lower: only $55 \%$ of the variance in $Q_{\min }$ was 477 explained. This suggests that although model parameters were strongly correlated with physical 478 characteristics in Australia, these relationships did not transfer to the US dataset. A number of 479 reasons could explain this negative result, in particular the consideration of snowmelt (see 480 below), and extrapolations of the regression outside the range of Australian values for a number 481 of physical characteristics (in particular soil variables and, to a lesser extent, climate variables).

482 However, after calibration, DWBM's performance was good for both total and minimum flows, 483 confirming the possibility to use the model with regional parameterization.

484 Because errors in $Q_{\min }$ were only weakly correlated with catchment characteristics, it is difficult 485 to predict where the model will perform best outside the set of catchments in Australia or the 486 US. However, the model seemed to perform better when the aridity index was lower (i.e. drier, 487 and thus minimum flows were lower), likely reflecting water-balance constraints in a water488 limited environment. Additionally, it is likely that snowmelt effects, ignored in this work, 489 contribute to errors in minimum flows. To test this hypothesis, we evaluated model performance 490 for the 97 US basins that were not influenced by snow precipitation (Guswa et al., 2017), and 491 found that $r^{2}$ increased to 0.70 (from 0.55 ) and 0.68 (from 0.51 ), respectively, for the "full 492 regression" and mean-value parameterizations (RMSE were $4.4 \mathrm{~mm}$ and $4.5 \mathrm{~mm}$, respectively). 493 These results confirm that the relationships did not transfer to the US dataset. We also 
494 hypothesized that performance would be higher where high values of $\alpha_{1}$ and $\alpha_{2}$ are predicted by 495 the regression, based on the sensitivity analyses, although the US dataset did not confirm this 496 hypothesis.

497 We conclude this section with methodological points that help interpret model performance, both 498 for absolute values or theoretical land-use change. First, we note that many catchments in our 499 datasets had low observed minimum flow $(<3 \mathrm{~mm} / \mathrm{mo})$, especially for the Australian dataset 500 dominated by the "humid temperate warm summer" climate zone. In absolute values, these 501 errors remain small as illustrated by Figure 4. In addition, the datasets included only "natural" 502 catchments, with the land use being mainly grassland or forest. This means that the effect of 503 different land uses is likely difficult to detect in these datasets, as suggested by the regressions 504 on catchment characteristics (forest cover was not significantly correlated with $\alpha_{1}$ or $\alpha_{2}$ ). This 505 could also explain the poor performance of the reduced regression model: variations in $\alpha_{1}$ and $506 \alpha_{2}$ based on the simple regression models were small (for example, CN values only varied from 50770 to 80 , a narrower range compared to possible land use changes involving agricultural land).

508 We also note that further analyses could improve model performance in both regions. First, the 509 model calibration could be focused on low flows. The calibration for the Australian dataset was 510 performed using a combination of four objective functions, with only one focused on low flows

511 (Zhang et al., 2008). Second, the parameter values could be corrected for the bias in $Q_{\min }$ for 512 the US dataset. This bias may be related to the calibration function, but our analyses do not 513 provide evidence of this.

\section{$514 \quad 5.2$ Predicting the effect of environmental change for ungauged catchments}

515 - Climate change

516 Both the US and Australian dataset comprise catchments that range in climate, geology, and 517 land use. The fair performance of the model in both locations suggests that the model is able to 
518 represent the variability of hydrological behavior induced by these factors. This gives confidence 519 that the effect of future climate forcing would be correctly represented: because the model uses 520 monthly climate time series as forcing variables, such analysis can be performed by substituting 521 current climate time series with future forecasts. Given the highest performance of the calibrated 522 model, climate change analyses are best performed with gauged catchments (calibrating the 523 model). However, they may be conducted on ungauged catchments too when information on a 524 relative change, rather than absolute, is sought. For example, Monte-Carlo-type analysis can be 525 performed by assuming parameter sets for the catchment of interest, and then running the 526 model for each set to provide upper and lower bounds of the expected change following climate 527 change.

528 - Land use change

529 The high performance of the full regression model in Australia was not found in the US.

530 Therefore, using model regression to infer parameter values is not a feasible option for 531 ungauged catchments globally. For the Australian dataset, $\mathrm{CN}$ and forest cover were found to 532 be important variables in the full regression on $\alpha_{1}$ (Section 4.2), confirming the relationship 533 between this parameter and land-use variables. For both regions, calibrated parameter values 534 showed low or no correlation with land-use variables, which suggest that additional work is 535 needed to derive empirical relationships between the parameter values and land use 536 characteristics. Nonetheless, the land-use change analyses in Section 4.6 suggest that one can 537 use the baseline provided by the model to compute the relative change in $\mathrm{Q}_{\min }$ following land538 use change. The motivation for this simple analysis was to understand, theoretically, the effect 539 of landscape interventions on dry-season flows. For example, such information can be used to 540 assess the potential for the "sponge effect" to occur in a given climate (i.e. that afforestation 541 would increase dry-season flow): specifically, the catchments with a relative change close to 
542 zero in Figure 6a are unlikely to demonstrate an increase in dry-season flow with afforestation,

543 since the change in a parameter values only minimally affected $Q_{\text {min }}$.

544 We note that the absolute change in parameter values can be constrained by the calibrated

545 parameter set, if regional data are available (e.g. the US and Australian datasets used in this

546 study). As suggested above, Monte-Carlo runs can be performed to provide confidence intervals

547 around the change in $Q_{\min }$. Additional work on the relationships between catchment

548 characteristics and parameter is in progress with catchments that have pre- and post-

549 afforestation streamflow data (Zhang et al., 2016). Preliminary results suggest that the

550 relationships hypothesized in Table 1 hold and that regional relationships can be used to predict

551 land-use change. The results also confirm that the land-use change signal (i.e. the increase in

552 forest cover, with all other variables held constant) may be confounded by other environmental

553 factors.

554

\section{Conclusion}

556 We have investigated how a simple rainfall-runoff model run at the monthly time step could

557 represent and predict the influence of climate and land-use change on dry-season flow. We

558 used the DWBM model, which assumes that streamflow, in particular during the dry season, is

559 driven by four main catchment characteristics: the retention efficiency of a catchment (ability to

560 store water for future release by discharge or evapotranspiration), evapotranspiration efficiency

561 (ability to use soil water for evapotranspiration rather than discharge), total soil storage, and

562 drainage rate. Our analyses confirmed that climate is a major driver of seasonal flows and that

563 the simple model DWBM, with default values obtained from the mean of calibrated catchments,

564 could provide a reasonable estimate of monthly flows. Model performance increases

565 significantly when calibration data are available, although in this work we found that regional 
566 relationships to infer model parameters could not transfer to other regions (the regression on 567 catchment properties obtained in Australian did not result in high performance in the US). Our 568 analyses also suggest that DWBM can be used to estimate a change in annual and minimum 569 monthly flow following environmental change. Even without calibration data, the effects of land 570 use change (e.g. reduction in retention efficiency or in evapotranspiration efficiency) can be 571 explored and quantitatively estimated. The effect of climate change can also be assessed, 572 preferably with a calibrated model if absolute values are sought. The broad range of

573 environmental conditions used in that study confirmed that the simple structure is able to 574 capture the main hydrological processes driving runoff response. The model has low data 575 requirements, and all climate data and catchment information used in this study are available 576 globally.

\section{Acknowledgements}

579 The authors are grateful for the support from The Natural Capital Project, with funding from 580 Google.org (grant \#172761).

\section{References}

583 Andréassian, V., 2004. Waters and forests: From historical controversy to scientific debate. J. $584 \quad$ Hydrol. 291, 1-27. doi:10.1016/j.jhydrol.2003.12.015

585 Boer, F. de, 2015. HiHydroSoil: A High Resolution Soil Map of Hydraulic Properties. Report 134; $586 \quad$ www.futurewater.nl.

587 Brauman, K.A., Richter, B.D., Postel, S., Malsy, M., Flörke, M., 2016. Water depletion: An 
588 improved metric for incorporating seasonal and dry-year water scarcity into water risk 589 assessments. Elem. Sci. Anthr. 4, 83. doi:10.12952/journal.elementa.000083

590 Breiman, L., 2001. Random Forests, in: Machine Learning. pp. 5-32.

591 doi:10.1023/A:1010933404324

592 Brown, A.E., Western, A.W., McMahon, T.A., Zhang, L., 2013. Impact of forest cover changes 593 on annual streamflow and flow duration curves. J. Hydrol. 483, 39-50.

$594 \quad$ doi:10.1016/j.jhydrol.2012.12.031

595 Brown, A.E., Zhang, L., McMahon, T. a., Western, A.W., Vertessy, R. a., 2005. A review of 596 paired catchment studies for determining changes in water yield resulting from alterations 597 in vegetation. J. Hydrol. 310, 28-61. doi:10.1016/j.jhydrol.2004.12.010

598 Brutsaert, W., 2008. Long-term groundwater storage trends estimated from streamflow records: 599 Climatic perspective. Water Resour. Res. 44, n/a-n/a. doi:10.1029/2007WR006518

600 Budyko, M., 1961. The Heat Balance of the Earth's Surface. Washington D.C.

601 Devito, K., Creed, I., Gan, T., Mendoza, C., Petrone, R., Silins, U., Smerdon, B., 2005. A 602 framework for broad-scale classification of hydrologic response units on the Boreal Plain : 603 is topography the last thing to consider ? Hydrol. Process. 19, 1705-1714. 604 doi:10.1002/hyp.5881

605 Gao, Z., Zhang, L., Cheng, L., Zhang, X., Cowan, T., Cai, W., Brutsaert, W., 2015. Groundwater 606 storage trends in the Loess Plateau of China estimated from streamflow records. J. Hydrol. $607 \quad 530,281-290$. doi:10.1016/j.jhydrol.2015.09.063

608 Gehne, M., Hamill, T., Kiladis, G.N., Trenberth, K.E., 2016. Comparison of Global Precipitation 609 Estimates across a Range of Temporal and Spatial Scales. J. Clim. 
610 Guswa, A., Brauman, K.A., Brown, C., Hamel, P., Keeler, B.L., Sayre, S.S., 2014. Ecosystem

611 Services: Challenges and Opportunities for Hydrologic Modeling to Support Decision

612 Making. Water Resour. Res. 50, 4535-4544. doi:10.1002/2014WR015497

613 Guswa, A.J., Hamel, P., Dennedy-Frank, P.J., 2017. Potential effects of landscape change on

614 water supplies in the presence of reservoir storage. Water Resour. Res.

615 Hamel, P., Guswa, A.J., 2015. Uncertainty analysis of a spatially-explicit annual water-balance 616 model: case study of the Cape Fear catchment, NC. Hydrol. Earth Syst. Sci. 19, 839-853. 617 doi:10.5194/hess-19-839-2015

618 Hughes, D.A., 2004. Incorporating groundwater recharge and discharge functions into an 619 existing monthly rainfall-runoff model/Incorporation de fonctions de recharge et de vidange 620 superficielle de nappes au sein d'un modèle pluie-débit mensuel existant. Hydrol. Sci. J. $621 \quad$ 49. doi:10.1623/hysj.49.2.297.34834

622 Jencso, K.G., McGlynn, B.L., 2011. Hierarchical controls on runoff generation: Topographically 623 driven hydrologic connectivity, geology, and vegetation. Water Resour. Res. 47, n/a-n/a. 624 doi:10.1029/2011WR010666

625 Kirby, J.M., Connor, J., Ahmad, M.D., Gao, L., Mainuddin, M., 2014. Climate change and 626 environmental water reallocation in the Murray-Darling Basin: Impacts on flows, diversions 627 and economic returns to irrigation. J. Hydrol. 518, 120-129.

628 doi:10.1016/j.jhydrol.2014.01.024

629 Kirchner, J.W., 2009. Catchments as simple dynamical systems: Catchment characterization, 630 rainfall-runoff modeling, and doing hydrology backward. Water Resour. Res. 45, W02429.

631 Mclntyre, N., Ballard, C., Bruen, M., Bulygina, N., Buytaert, W., Cluckie, I., Dunn, S., Ehret, U., 632 Ewen, J., Gelfan, A., Hess, T., Hughes, D., Jackson, B., Kjeldsen, T., Merz, R., Park, J., 
633 Connell, E.O., Donnell, G.O., Oudin, L., Todini, E., Wagener, T., Wheater, H., Mcintyre, N., 634 2014. Modelling the hydrological impacts of rural land use change. Hydrol. Res. 45, 737635 754. doi: $10.2166 /$ nh. 2013.145

636 Mouelhi, S., Michel, C., Perrin, C., Andréassian, V., 2006. Stepwise development of a two637 parameter monthly water balance model. J. Hydrol. 318, 200-214.

638 doi:10.1016/j.jhydrol.2005.06.014

639 Newman, A.J., Clark, M.P., Sampson, K., Wood, A., Hay, L.E., Bock, A., Viger, R.J., Blodgett, 640 D., Brekke, L., Arnold, J.R., Hopson, T., Duan, Q., 2015. Development of a large-sample 641 watershed-scale hydrometeorological data set for the contiguous USA: data set 642 characteristics and assessment of regional variability in hydrologic model performance. 643 Hydrol. Earth Syst. Sci. 19, 209-223. doi:10.5194/hess-19-209-2015

644 NRCS-USDA, 2004. Chapter 10. Estimation of Direct Runoff from Storm Rainfall, in: United 645 States Department of Agriculture (Ed.), Part 630 Hydrology. National Engineering $646 \quad$ Handbook. United States Department of Agriculture, 647 http://www.nrcs.usda.gov/wps/portal/nrcs/detailfull/national/water/?cid=stelprdb1043063.

648 Perrin, C., Michel, C., Andréassian, V., 2001. Does a large number of parameters enhance 649 model performance? Comparative assessment of common catchment model structures on 650429 catchments. J. Hydrol. 242, 275-301. doi:http://doi.org/10.1016/S0022$651 \quad 1694(00) 00393-0$

652 Price, K., 2011. Effects of watershed topography, soils, land use, and climate on baseflow 653 hydrology in humid regions: A review. Prog. Phys. Geogr. 35, 465-492. doi:DOI:

$654 \quad 10.1177 / 0309133311402714$

655 Shao, Q., Traylen, A., Zhang, L., 2012. Nonparametric method for estimating the effects of 
656 climatic and catchment characteristics on mean annual evapotranspiration. Water Resour.

657 Res. 48, 1-13. doi:10.1029/2010WR009610

658 Smakhtin, V.., Hughes, D., 2007. Automated estimation and analyses of meteorological drought 659 characteristics from monthly rainfall data. Environ. Model. Softw. 22, 880-890.

660 doi:10.1016/j.envsoft.2006.05.013

661 Smith, M.B., Seo, D.-J., Koren, V.I., Reed, S.M., Zhang, Z., Duan, Q., Moreda, F., Cong, S., 662 2004. The distributed model intercomparison project (DMIP): motivation and experiment 663 design. J. Hydrol. 298, 4-26. doi:10.1016/j.jhydrol.2004.03.040

664 Vogl, A.L., Dennedy-Frank, P.J., Wolny, S., Johnson, J.A., Hamel, P., Narain, U., Vaidya, A., 665 2016. Managing forest ecosystem services for hydropower production. Environ. Sci. Policy $666 \quad 61,221-229$.

667 Wang, Q.J., Pagano, T.C., Zhou, S.L., Hapuarachchi, H. a P., Zhang, L., Robertson, D.E., 2011. 668 Monthly versus daily water balance models in simulating monthly runoff. J. Hydrol. 404, 669 166-175. doi:10.1016/j.jhydrol.2011.04.027

670 Zhang, L., Brutsaert, W., Crosbie, R., Potter, N., 2014. Long-term annual groundwater storage 671 trends in Australian catchments. Adv. Water Resour. 74, 156-165.

672 doi:10.1016/j.advwatres.2014.09.001

673 Zhang, L., Hickel, K., Shao, Q., 2016. Predicting afforestation impacts on monthly streamflow 674 using the DWBM model. Ecohydrology 10. doi:10.1002/eco.1821

675 Zhang, L., Potter, N., Hickel, K., Zhang, Y., Shao, Q., 2008. Water balance modeling over 676 variable time scales based on the Budyko framework - Model development and testing. J. $677 \quad$ Hydrol. 360, 117-131. doi:10.1016/j.jhydrol.2008.07.021 
678

679

680 


\section{Appendix}

\section{A. Sensitivity analysis}

683 We performed the sensitivity analyses with actual data from three climatically distinct locations:

684 (1) Nairobi, Kenya, (2) San Jose, Costa Rica, and (3) Cleveland, USA. Under the Köppen-

685 Geiger climate classification, Nairobi has a subtropical highland climate with dry summers and

686 an annual aridity index of 0.47 ; San Jose has a tropical climate, with dry winter and an aridity

687 index of 1.6; Cleveland has a humid continental climate with an aridity index of 2.4. Although we

688 could have used synthetic climate series to control climate variability, our objective here is to

689 illustrate model behaviors under different climate forcing, which is achieved by actual data from

690 different climate zones.

- Methods

692 Monthly precipitation and temperature data were acquired for each of these locations from the

693 National Oceanic and Atmospheric Administration's (NOAA) Global Historical Climatology

694 Network-Monthly (GHCN-M) dataset. From this dataset, we computed monthly averages. The

695 precipitation averages were used directly as model input, while the temperature averages were

696 used to calculate monthly potential evapotranspiration (PET) values using the modified

697 Hargreaves method (equation (5) from Droogers, et al., 2002). The precipitation and potential

698 evapotranspiration time series for each location are shown in Figure A1.

699 For each climate type, we first performed a one-at-a-time sensitivity analysis, using five levels at 700 equal intervals for each parameter. The range for each parameter was initially based on the 701 values obtained from the model calibration by Zhang et al. (2008), described in further details in 702 Section 3, and summarized in Table A1. Initial conditions affected flows for only the first few 
703 years: to remove this 'warm-up' effect, the model was run for 10 years, repeating the same

704 climate forcing, and only the final year was used to compute the statistics.

705 Next, to quantify interaction effects among parameters, the model was run 24 additional times

706 for each climate type, varying every possible pair of parameters with all possible combinations

707 of upper and lower bounds for each parameter.

708 After computing the regression analyses (cf. Section 3.1), we also re-ran the one-at-a-time 709 sensitivity analyses varying mean values of each parameter by the average error in the random

710 forest model: the new range (twice the average parameter error around the mean value) gives a

711 more realistic assessment of sensitivity for the Australian dataset, and is plotted on Figure 3.

\section{2 [TABLE A1 and FIGURE A1]}

713 - Results

714 In general, for the humid continental climate (Cleveland), total flow and minimum flow $\left(Q_{\min }\right)$

715 were not very sensitive to model parameters (Figure 3). The highest change in $\mathrm{Q}_{\min }$ was $42 \%$,

716 obtained for the minimum value of $\alpha_{2}$. We note that in absolute value, effects of parameter

717 change were more significant than for other climates: for example, the $42 \%$ change in $Q_{\min }$

718 represented $23 \mathrm{~mm} / \mathrm{mo}$. Larger variations in the relative sensitivity were observed for the two

719 other climate types.

$720 \boldsymbol{\alpha}_{1}$ In the tropical dry winter (San Jose) and subtropical dry summer (Nairobi) climates, $Q_{\min }$ was

721 sensitive to increases in $\alpha_{1}$ (with a maximum change of $53 \%$ ) due to less direct flow during and

722 slightly after each precipitation event. In Nairobi, $Q_{\min }$ was more sensitive to low values of $\alpha_{1}$ :

723 decreasing $\alpha_{1}$ lowers the baseflow contribution to streamflow significantly by reducing the

724 amount of water that is retained in soil storage, and thus in groundwater storage. 
$725 \boldsymbol{\alpha}_{2}$. In the tropical and subtropical climates, $Q_{\min }$ decreased as $\alpha_{2}$ increased (-83\% and $-96 \%$, 726 respectively), due to a larger portion of water being evapotranspired. $Q_{\min }$ was sensitive to lower 727 values of $\alpha_{2}$ in Nairobi (subtropical dry-summer), since evapotranspiration demand is high when 728 flows are low.

$729 S_{\max }$. In all three climates, $Q_{\min }$ showed little sensitivity to $S_{\max }$. Lower values tended to increase $730 Q_{\min }$ in Nairobi, since they increased evapotranspiration opportunity (i.e. evapotranspiration and 731 recharge) in an arid environment. Conversely, lower values tended to decrease $Q_{\min }$ in San 732 Jose (tropical dry-winter) where water availability is higher, and low soil storage increased the 733 ratio of direct runoff over recharge.

734 d. As expected, $Q_{\min }$ was highly sensitive to $d$ in seasonal climates (subtropical and tropical). In 735 particular, lower values of $d$ resulted in sharp increases in $Q_{\min }$, since the slow groundwater 736 release sustained a high baseflow throughout the year.

737 Interaction effects showed mostly subadditive effects. Only low values of $d$ tended to exacerbate 738 sensitivity to $S_{\max }$ or $\alpha_{2}$, while low values of $S_{\max }$ tended to exacerbate sensitivity to $\alpha_{1}$ or $\alpha_{2}$.

739

740 B. Quality assurance of Newman's dataset (2015)

$741 \quad$ [TABLE B1] 


\section{TABLES}

743 Table 1. Parameters and physical interpretation of DWBM. + and ++ indicate the strength of the likely

744 effect of land use change (LUC) and climate change (CC) on the parameters. Numbers in brackets are 745 coefficients obtained from a stepwise backward linear regression between calibrated parameter values 746 and forest cover (for LUC), or number of wet days (for CC) (* indicates significance at the 0.1 level, ** 747 significance at the 0.01 level). See text and Table 2 for a definition of these variables.

\begin{tabular}{|c|c|c|c|}
\hline Parameter & Description & $\begin{array}{l}\text { Affected by } \\
\text { LUC }\end{array}$ & $\begin{array}{l}\text { Affected by } \\
\text { CC }\end{array}$ \\
\hline $\begin{array}{l}S_{\max } \\
{[5 ; 500] \mathrm{mm}}\end{array}$ & $\begin{array}{l}\text { Maximum catchment storage capacity. } \\
\text { Depends on: soil depth and available water content } \\
\text { (measurable soil characteristics) }\end{array}$ & $\begin{array}{l}+ \\
{[0.71]^{*}}\end{array}$ & $\begin{array}{l}+ \\
{[-309]^{*}}\end{array}$ \\
\hline$\alpha_{1}[0 ; 1]$ & $\begin{array}{l}\text { Catchment retention; affects the partitioning of } \\
\text { precipitation into direct runoff and water that is available } \\
\text { in the soil-moisture store (S) for evapotranspiration and } \\
\text { groundwater recharge. } \\
\text { Depends on: the soil infiltration capacity and the rainfall } \\
\text { intensity (more intense, less frequent events means more } \\
\text { direct runoff). }\end{array}$ & $\begin{array}{l}++ \\
{\left[1.8 e^{-4}\right]}\end{array}$ & $\begin{array}{l}++ \\
{[-0.15]}\end{array}$ \\
\hline$\alpha_{2}[0 ; 1]$ & $\begin{array}{l}\text { Evapotranspiration efficiency; affects the partitioning of } \\
\text { soil water into storage, recharge, and actual } \\
\text { evapotranspiration. } \\
\text { Depends on: the rainfall frequency, plant water-stress } \\
\text { response, root depth, and soil properties such as } \\
\text { hydraulic conductivity and critical moisture content (at } \\
\text { which actual evapotranspiration is reduced for water }\end{array}$ & $\begin{array}{l}++ \\
{\left[4.1 \mathrm{e}^{-4}\right]}\end{array}$ & $\begin{array}{l}+ \\
{[-0.30]^{* *}}\end{array}$ \\
\hline
\end{tabular}


2

3

4

5

6

7

8

9

10

stress). Note that $\alpha_{2}$ does not depend on the crop

coefficient, which is already included in PET

d $[0 ; 1] \quad G r o u n d w a t e r$ store time constant; characterizes the n.a.

month $^{-1} \quad$ groundwater drainage rate, ie the release of groundwater

storage to baseflow. Note that $\mathrm{d}$ does not affect

partitioning, only timing of baseflow.

Depends on: aquifer characteristics (size, hydraulic

conductivity, connectivity with the stream)

748

749 Table 2. Catchment characteristics assessed in this study

\begin{tabular}{|c|c|c|c|}
\hline & Abbreviation & Name & Description \\
\hline \multirow[t]{6}{*}{ Climate } & $\mathbf{P}$ & $\begin{array}{l}\text { Precipitation } \\
\text { (mm/month) }\end{array}$ & Monthly rainfall \\
\hline & Aridity & Aridity (-) & $\begin{array}{l}\text { Precipitation divided by } \\
\text { Potential Evapotranspiration }\end{array}$ \\
\hline & Peomonths & $\begin{array}{l}\text { Difference in peak } \\
\text { potential } \\
\text { evapotranspiration and } \\
\text { precipitation (month) }\end{array}$ & $\begin{array}{l}\text { The number of months that } \\
\text { peak precipitation follows } \\
\text { peak potential } \\
\text { evapotranspiration }\end{array}$ \\
\hline & ASD & $\begin{array}{l}\text { Average Storm Depth } \\
\text { (mm/day) }\end{array}$ & Depth of the average storm \\
\hline & WetDays & $\begin{array}{l}\text { Proportion of Wet Days } \\
(-)\end{array}$ & $\begin{array}{l}\text { Proportion of days per year } \\
\text { with some precipitation }\end{array}$ \\
\hline & CVP & $\begin{array}{l}\text { Coefficient of Variation } \\
\text { of Precipitation (-) }\end{array}$ & $\begin{array}{l}\text { The standard deviation (of } \\
\text { interannual precipitation) } \\
\text { divided by the average }\end{array}$ \\
\hline
\end{tabular}




\begin{tabular}{|c|c|c|c|}
\hline & & & annual rainfall \\
\hline \multirow[t]{2}{*}{ Vegetation } & forest & Forest Cover (\%) & $\begin{array}{l}\text { Percent of catchment area } \\
\text { covered by forest }\end{array}$ \\
\hline & $\mathrm{CN}$ & Curve Number & $\begin{array}{l}\text { Curve Number from the SCS } \\
\text { method (also a function of } \\
\text { soil group) }\end{array}$ \\
\hline Topography & $\mathbf{R r}$ & Relief Ratio (m/m) & $\begin{array}{l}\text { Total catchment relief divided } \\
\text { by the longest flow path }\end{array}$ \\
\hline \multirow[t]{4}{*}{ Soil } & soil_ksat_top & $\begin{array}{l}\text { Hydraulic Conductivity } \\
\text { for topsoil }(\mathrm{m} / \mathrm{s})\end{array}$ & $\begin{array}{l}\text { Saturated hydraulic } \\
\text { conductivity from } 0-30 \mathrm{~cm} \\
\text { depth }\end{array}$ \\
\hline & soil_ksat_sub & $\begin{array}{l}\text { Hydraulic Conductivity, } \\
\text { subsoil (m/s) }\end{array}$ & $\begin{array}{l}\text { Saturated hydraulic } \\
\text { conductivity from } 30-200 \mathrm{~cm} \\
\text { depth }\end{array}$ \\
\hline & soil_sat_wc & $\begin{array}{l}\text { Saturated Water } \\
\text { Content }\left(\mathrm{m}^{3} / \mathrm{m}^{3}\right)\end{array}$ & $\begin{array}{l}\text { Maximum fraction of soil } \\
\text { volume that can be occupied } \\
\text { by water }\end{array}$ \\
\hline & PAWHC & $\begin{array}{l}\text { Plant Available Water } \\
\text { Holding Capacity (mm) }\end{array}$ & $\begin{array}{l}\text { Maximum depth of soil water } \\
\text { that is available for removal } \\
\text { by vegetation }\end{array}$ \\
\hline
\end{tabular}

751 Table 3. Calibrated parameter values and strength of the correlation ( $r^{2}$ and mean absolute error, MAE)

752 between calibrated parameters and their estimates from the full regression and reduced regression

753 methods, for the Australian dataset.

\begin{tabular}{c|c|c|c|c|}
\hline & $\boldsymbol{\alpha}_{1}$ & $\boldsymbol{\alpha}_{\mathbf{2}}$ & $\mathbf{S}_{\max }(\mathbf{m m})$ & $\mathbf{d}\left(\mathbf{m o n t h}^{-1}\right)$ \\
\hline Mean and range (calibrated & 0.62 & 0.74 & 258 & 0.66 \\
\hline
\end{tabular}




\begin{tabular}{|c|c|c|c|c|c|}
\hline \multicolumn{2}{|c|}{ values) } & {$[0.40 ; 0.74]$} & {$[0.42 ; 0.80]$} & {$[36.5 ; 500]$} & {$[0.10 ; 1]$} \\
\hline Full & $r^{2}$ & 0.95 & 0.96 & 0.95 & 0.96 \\
\hline Regression & & & & & 0.10 \\
regression & MAE & 0.017 & 0.022 & 34 & 0.06 \\
\hline
\end{tabular}

754

755 Table 4. Performance statistics, $r^{2}$ and root mean square error (RMSE), for the four model

756 parameterizations for the Australian and US catchments

\begin{tabular}{|c|c|c|c|c|c|c|c|c|}
\hline & \multicolumn{4}{|c|}{ Australia } & \multicolumn{4}{|l|}{ US } \\
\hline & $\begin{array}{l}Q_{\text {tot }} \\
r^{2}\end{array}$ & RMSE & $\begin{array}{l}\mathrm{Q}_{\min } \\
\mathrm{r}^{2}\end{array}$ & RMSE & $\begin{array}{l}Q_{\text {tot }} \\
r^{2}\end{array}$ & RMSE & $\begin{array}{l}\mathrm{Q}_{\min } \\
\mathrm{r}^{2}\end{array}$ & RMSE \\
\hline Calibration & 0.98 & 42.4 & 0.90 & 2.4 & 0.96 & 108.9 & 0.88 & 9.29 \\
\hline Full regression & 0.96 & 47.8 & 0.84 & 2.3 & 0.92 & 167.5 & 0.55 & 9.92 \\
\hline Reduced regression & 0.87 & 88.6 & 0.53 & 3.9 & 0.92 & 159.3 & 0.53 & 9.37 \\
\hline Mean & 0.87 & 89.5 & 0.55 & 4.0 & 0.92 & 173.2 & 0.51 & 9.34 \\
\hline
\end{tabular}

757

758 Table A1. Parameter levels used in the sensitivity analyses, corresponding to the minimum, $25^{\text {th }}, 50^{\text {th }}$, and $75975^{\text {th }}$ percentiles, and maximum parameter values.

\section{Parameter}

Min

25th

50th

75th

$\operatorname{Max}$ 


\begin{tabular}{|c|ccccc|} 
Smax (mm) & 133 & 200 & 266 & 333 & 399 \\
$\alpha_{1}$ & 0.30 & 0.45 & 0.60 & 0.75 & 0.90 \\
$\alpha_{2}$ & 0.30 & 0.45 & 0.60 & 0.75 & 0.90 \\
$d$ & 0.33 & 0.5 & 0.66 & 0.83 & 1.0 \\
\hline
\end{tabular}

761 Table B1. List of basins removed from Newman's dataset (Newman et al., 2015), due to issues with the

762 time series. Other basins showed short gaps in the time series but the effect on the long-term average

763 was deemed minor. $R$ is the reported average daily runoff in

764 basin_annual_hydrometeorology_characteristics_daymet.txt (from Newman et al.'s dataset); $P$ is the

765 reported average daily precipitation in basin_annual_hydrometeorology_characteristics_daymet.txt; $<q>$

766 is the calculated average runoff from daily discharge and basin area; $\langle p\rangle$ is the calculated average

767 precipitation from daily precipitation

\begin{tabular}{|l|l|}
\hline \multicolumn{1}{|c|}{ Basin } & \multicolumn{1}{|c|}{ Issue } \\
\hline 0302108000 & $\begin{array}{l}\text { Area and elevation in basin_characteristics file do } \\
\text { not match USGS website or information in gage } \\
\text { information file }\end{array}$ \\
\hline $\begin{array}{l}0302310947 \\
\text { Withlacoochee River near Cumpressco, FL Fear, NC }\end{array}$ & $\begin{array}{l}\text { Multiple, long, discontinuous gaps in the } \\
\text { streamflow record }\end{array}$ \\
\hline $\begin{array}{l}0302381600 \\
\text { Fausett Creek near Talking Rock, GA }\end{array}$ & $\begin{array}{l}\text { Calculated average runoff from daily values, }<\mathrm{q}> \\
\text { is }>1.5^{\star} \text { reported average daily runoff, } \mathrm{R}\end{array}$ \\
\hline $\begin{array}{l}0503357350 \\
\text { Plum Creek near Bainbridge, IN }\end{array}$ & $\begin{array}{l}\text { Calculated runoff from daily values, }<\mathrm{q}>\text {, is less } \\
\text { than } 50 \% \text { of reported average daily runoff, } \mathrm{R}\end{array}$ \\
\hline 0905062500 & Calculated average runoff from daily values, $<\mathrm{q}>$ \\
\hline
\end{tabular}




\begin{tabular}{|c|c|}
\hline Wild Rice River at Twin Valley, MN & is $>1.5^{*}$ reported average daily runoff, $R$ \\
\hline $\begin{array}{l}0905087500 \\
\text { Middle River at Argyle, MN }\end{array}$ & $\begin{array}{l}\text { Calculated average runoff from daily values, }<q> \\
\text { is }>1.5^{\star} \text { reported average daily runoff, } R\end{array}$ \\
\hline $\begin{array}{l}0905120500 \\
\text { Wintering River near Karlsruhe, ND }\end{array}$ & $\begin{array}{l}\text { Calculated runoff from daily values, }\langle q\rangle \text {, is less } \\
\text { than } 50 \% \text { of reported average daily runoff, } R\end{array}$ \\
\hline $\begin{array}{l}1006468250 \\
\text { James River near Kensal, ND }\end{array}$ & $\begin{array}{l}\text { Calculated runoff from daily values, }\langle q>\text {, is less } \\
\text { than } 50 \% \text { of reported average daily runoff, } R\end{array}$ \\
\hline $\begin{array}{l}1006441500 \\
\text { Bad River near Fort Pierre, SD }\end{array}$ & Multiple long gaps in streamflow record \\
\hline $\begin{array}{l}1107067000 \\
\text { Current River at Van Buren, MO }\end{array}$ & $\begin{array}{l}\text { Area and elevation in basin_characteristics file do } \\
\text { not match USGS website or information in gage } \\
\text { information file }\end{array}$ \\
\hline $\begin{array}{l}1208079600 \\
\text { Brazos River at Justiceburg, TX }\end{array}$ & $\begin{array}{l}\text { Calculated runoff from daily values, }\langle q>\text {, is less } \\
\text { than } 50 \% \text { of reported average daily runoff, } R\end{array}$ \\
\hline $\begin{array}{l}1509484000 \\
\text { Sabino Creek near Tucson, AZ }\end{array}$ & $\begin{array}{l}\text { Multiple extended gaps in streamflow record } \\
\text { throughout }\end{array}$ \\
\hline $\begin{array}{l}1509492400 \\
\text { East Fork White River near Apache, AZ }\end{array}$ & $\begin{array}{l}\text { Calculated average runoff from daily values, }<q> \\
\text { is }>1.5^{\star} \text { reported average daily runoff, } R\end{array}$ \\
\hline $\begin{array}{l}1610166430 \\
\text { West Canyon Creek near Cedar Fort, UT }\end{array}$ & $\begin{array}{l}\text { Calculated runoff from daily values, }\langle q>\text {, is less } \\
\text { than } 50 \% \text { of reported average daily runoff, } R\end{array}$ \\
\hline $\begin{array}{l}1610172700 \\
\text { Vernon Creek near Vernon, UT }\end{array}$ & $\begin{array}{l}\text { Calculated runoff from daily values, }<q>\text {, is less } \\
\text { than } 50 \% \text { of reported average daily runoff, } R\end{array}$ \\
\hline $\begin{array}{l}1610172800 \\
\text { South Willow Creek near Grantsville, UT }\end{array}$ & $\begin{array}{l}\text { Calculated runoff from daily values, }\langle q\rangle \text {, is less } \\
\text { than } 50 \% \text { of reported average daily runoff, } R\end{array}$ \\
\hline 1610242000 & Calculated runoff from daily values, $\langle q\rangle$, is less \\
\hline
\end{tabular}




\begin{tabular}{|c|c|}
\hline Coal Creek near Cedar City, UT & than $50 \%$ of reported average daily runoff, $R$ \\
\hline $\begin{array}{l}1610249300 \\
\text { South Twin River nr Round Mountain, NV }\end{array}$ & $\begin{array}{l}\text { Calculated runoff from daily values, }\langle q\rangle \text {, is less } \\
\text { than } 50 \% \text { of reported average daily runoff, } R\end{array}$ \\
\hline $\begin{array}{l}1810259200 \\
\text { Deep Creek near Palm Desert, CA }\end{array}$ & $\begin{array}{l}\text { Calculated runoff from daily values, }\langle q\rangle \text {, is less } \\
\text { than } 50 \% \text { of reported average daily runoff, } R\end{array}$ \\
\hline $\begin{array}{l}1810263500 \\
\text { Big Rock Creek near Valyermo, CA }\end{array}$ & $\begin{array}{l}\text { Calculated runoff from daily values, }\langle q\rangle \text {, is less } \\
\text { than } 50 \% \text { of reported average daily runoff, } R\end{array}$ \\
\hline $\begin{array}{l}1811253310 \\
\text { Cantua Creek near Cantua Creek, CA }\end{array}$ & $\begin{array}{l}\text { Calculated runoff from daily values, }\langle q\rangle \text {, is less } \\
\text { than } 50 \% \text { of reported average daily runoff, } R\end{array}$ \\
\hline $\begin{array}{l}1712040500 \\
\text { Queets River nr Clearwater, WA }\end{array}$ & $\begin{array}{l}\text { Runoff ratio is greater than } 1 ;<q>\text { is greater than } \\
<p>\end{array}$ \\
\hline $\begin{array}{l}1712041200 \\
\text { Hoh River nr Forks, WA }\end{array}$ & $\begin{array}{l}\text { Runoff ratio is greater than } 1 ;<q>\text { is greater than } \\
<p>\end{array}$ \\
\hline $\begin{array}{l}1712056500 \\
\text { NF Skokomish River near Hoodsport, WA }\end{array}$ & $\begin{array}{l}\text { Runoff ratio is greater than } 1 ;<q>\text { is greater than } \\
<p>\end{array}$ \\
\hline $\begin{array}{l}1712147500 \\
\text { NF Tolt River near Carnation, WA }\end{array}$ & $\begin{array}{l}\text { Runoff ratio is greater than } 1 ;<q>\text { is greater than } \\
<p>\text { and } R \text { is greater than } P\end{array}$ \\
\hline $\begin{array}{l}1712147600 \\
\text { SF Tolt River near Index, WA }\end{array}$ & Runoff ratio greater than $1 ; \mathrm{R}$ is greater than $\mathrm{P}$ \\
\hline $\begin{array}{l}1712167000 \\
\text { NF Stillaguamish River near Arlington, WA }\end{array}$ & $\begin{array}{l}\text { Runoff ratio greater than } 1 ;<q>\text { is greater than } \\
<p>\text { and } R \text { is greater than } P\end{array}$ \\
\hline $\begin{array}{l}1712186000 \\
\text { Sauk River near Darrington, WA }\end{array}$ & $\begin{array}{l}\text { Runoff ratio greater than } 1 ;<q>\text { is greater than } \\
<p>\text { and } R \text { is greater than } P\end{array}$ \\
\hline $\begin{array}{l}1714158500 \\
\text { McKenzie River near Clear Lake, OR }\end{array}$ & $\begin{array}{l}\text { Runoff ratio greater than } 1 ;<q>\text { is greater than } \\
<p>\end{array}$ \\
\hline
\end{tabular}


1
2
3
4
5
6
7
8
9

10

1

12

13

14

15

16

17

18

19

20

21

22

23

24

25

26

27

28

29

30

31

32

33

34

35

36

37

38

39

40

41

42

43

44

45

46

47

48

49

50

51

52

53

54

55

56

57

58

59

60
Runoff ratio greater than $1 ;<q>$ is greater than

$<p>$ and $R$ is greater than $P$

\section{8}

769

770

1714400000

Brookings, OR 


\section{FIGURES}

772 Figure 1. "Limits" concept used for water partitioning in DWBM. The concept is used to partition both the

773 precipitation $(P)$ between wetting $(W)$ and direct runoff, and the wetting between evapotranspiration (ET)

774 and storage. The a parameters determine how close the variables are from their limits (dashed lines).

775

776 Figure 2. Distribution of the 89 Australian (left) and 641 US (right) catchments used in this study, with

777 associated aridity index values. Grey-scale background on the US map delineate the HUC2 regions

778 (darker colors represent higher HUC number).

779

780 Figure 3. Sensitivity of minimum flow $\left(Q_{\min }\right)$ to each model parameter. Grey lines represent the relative 781 error in parameter values from the regression model (Section 3.1)

782

783 Figure 4. Comparison of observed minimum flow $Q_{m i n}$, with predictions from the calibrated and mean784 value parameterizations for Australian catchments. Note that the plot window excludes between 12 and 78516 catchments with high values of $Q_{\min }$. rmse=root mean square error in $\mathrm{mm} / \mathrm{mo}$

787 Figure 5. Comparison of observed minimum flow $Q_{\min }$, with predictions from the calibrated and mean-

788 value parameterizations for US catchments. Note that the plot window excludes between 12 and 16

789 catchments with high values of $Q_{\min }$. rmse=root mean square error in $\mathrm{mm} / \mathrm{mo}$

790

791 
1

2

3

4

5

6

7

8

9

10

11

12

13

14

15

16

17

18

19

20

21

22

23

24

25

26

27

28

29

30

31

32

33

34

35

36

37

38

39

40

41

42

43

44

45

46

47

48

49

50

51

52

53

54

55

56

57

58

59

60

792 Figure 6. Predictions for $Q_{\min }$ (a) and $Q_{\text {tot }}$ (b) resulting from a hypothetical land use change - i.e. a change

793 in $\alpha_{1}$ and $\alpha_{2}$ values - for both the calibrated and the mean-value models. Each point represents one

794 catchment under either $10 \%$ (black) or $20 \%$ (grey) relative increase or decrease in $\alpha_{1}$ and $\alpha_{2}$. All values in

795 the bottom-left quadrant represent an increase in $\alpha_{1}$ and $\alpha_{2}$, while all values in the top-right quadrant

796 represent a decrease in the two parameters. Dashed lines represent a 50\% difference between the

797 calibrate and mean-value predictions. RMSE for $Q_{\min }$ is 0.36 for the " $10 \%$ change" and 1.2 for " $20 \%$

798 change". For the increase in $\alpha_{1}$ and $\alpha_{2}$ (bottom-left quadrant), representing afforestation, RMSE for " $20 \%$

799 change" is 0.13 .

800

801 Figure A1. Climate types used in this study: humid continental (Cleveland), subtropical with dry-summer

802 (Nairobi), tropical with dry-winter (San Jose)

803 
Figure 1. "Limits" concept used for water partitioning in DWBM. The concept is used to partition both the precipitation $(P)$ between wetting $(W)$ and direct runoff, and the wetting between evapotranspiration (ET) and storage. The $\alpha$ parameters determine how close the variables are from their limits (dashed lines).

http://mc.manuscriptcentral.com/hyp 
Figure 2. Distribution of the 89 Australian (left) and 641 US (right) catchments used in this study, with associated aridity index values. Grey-scale background on the US map delineate the HUC2 regions (darker colors represent higher HUC number). 
Hydrological Processes

Page 48 of 52

$$
\begin{aligned}
& 1 \\
& 2 \\
& 3 \\
& 4 \\
& 5 \\
& 6 \\
& 7 \\
& 8 \\
& 9 \\
& 10 \\
& 11 \\
& 12 \\
& 13 \\
& 14 \\
& 15 \\
& 16 \\
& 17 \\
& 18 \\
& 19 \\
& 20 \\
& 21 \\
& 22 \\
& 23 \\
& 24 \\
& 25 \\
& 26 \\
& 27 \\
& 28 \\
& 29 \\
& 30 \\
& 31 \\
& 32 \\
& 33 \\
& 34 \\
& 35 \\
& 36 \\
& 37 \\
& 38 \\
& 39 \\
& 40 \\
& 41 \\
& 42 \\
& 43 \\
& 44 \\
& 45 \\
& 46 \\
& 47 \\
& 48 \\
& 49 \\
& 50 \\
& 51 \\
& 52 \\
& 53 \\
& 54 \\
& 56 \\
&
\end{aligned}
$$
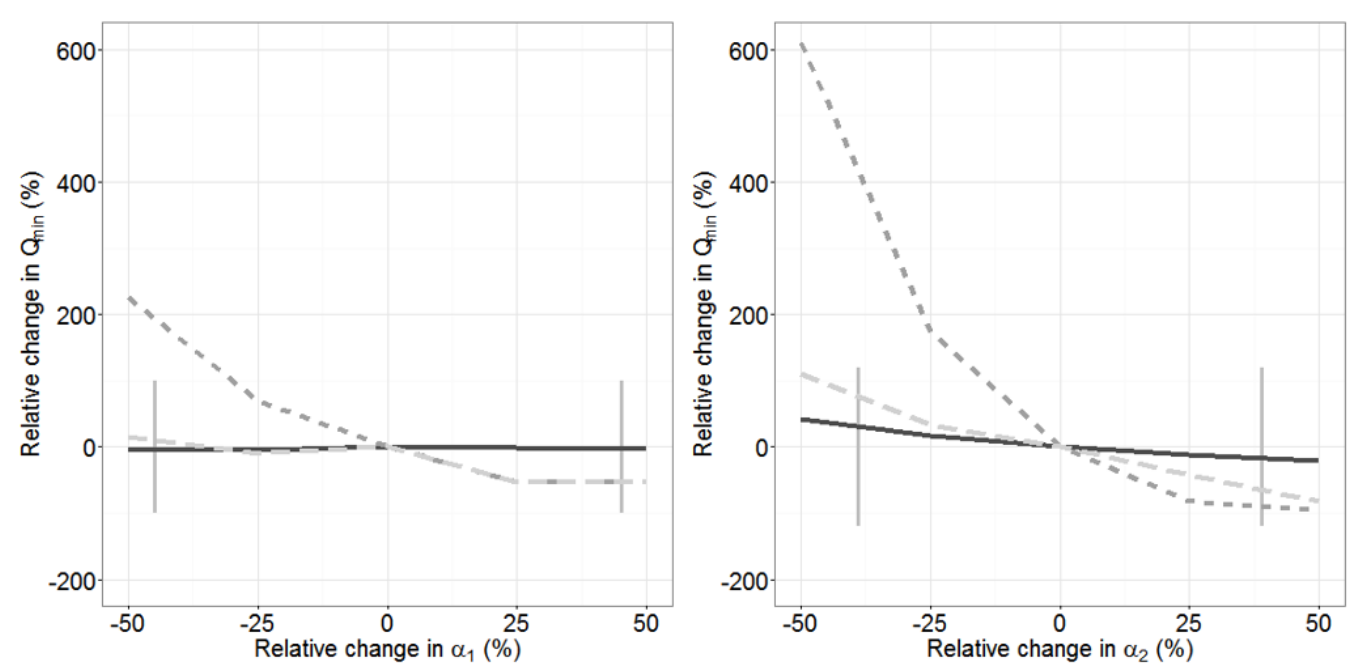

- Humid continental - Subtrop. dry summer - Tropical dry winter
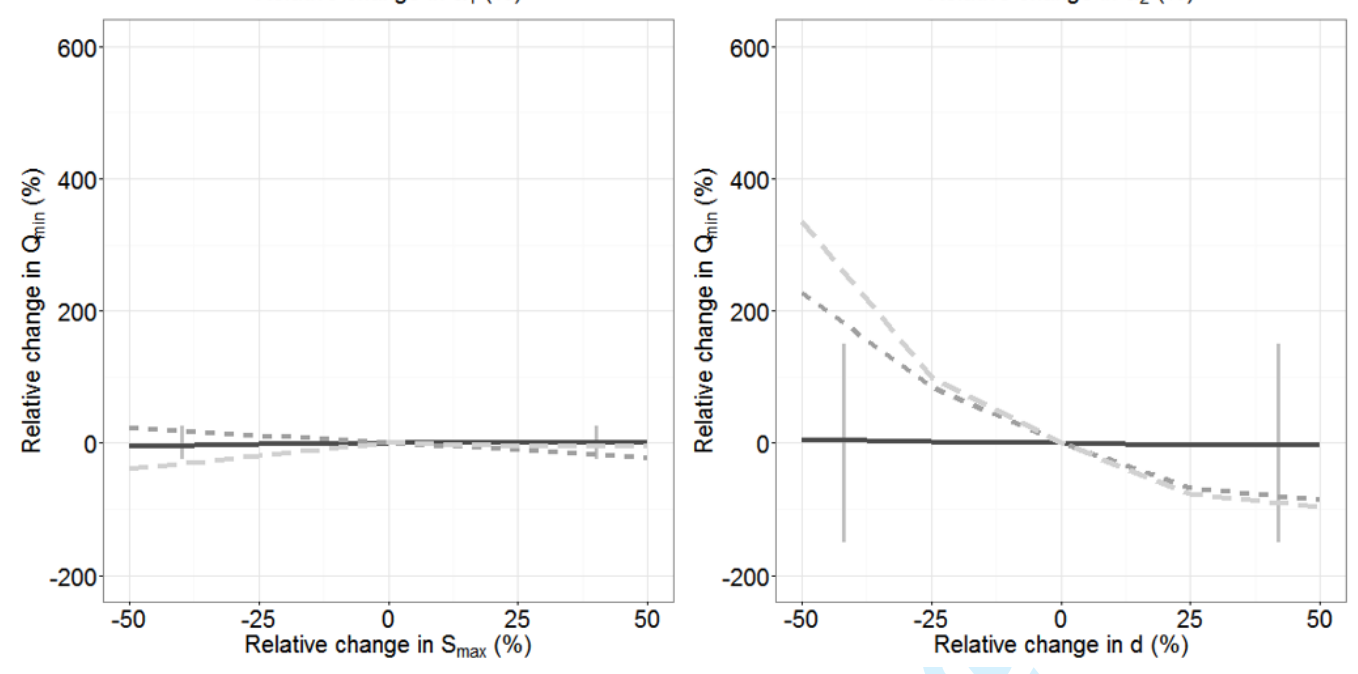

Figure 3. Sensitivity of minimum flow $\left(Q_{\min }\right)$ to each model parameter. Grey lines represent the relative error in parameter values from the regression model (Section 3.1)

http://mc.manuscriptcentral.com/hyp 
1

2

3

4

5

6

7

8

9

10

11

12

13

14

15

16

17

18

19

20

21

22

23

24

25

26

27

28

29

30

31

32

33

34

35

36

37

38

39

40

41

42

43

44

45

46

47

48

49

50

51

52

53

54

55

56

57

58

59

60
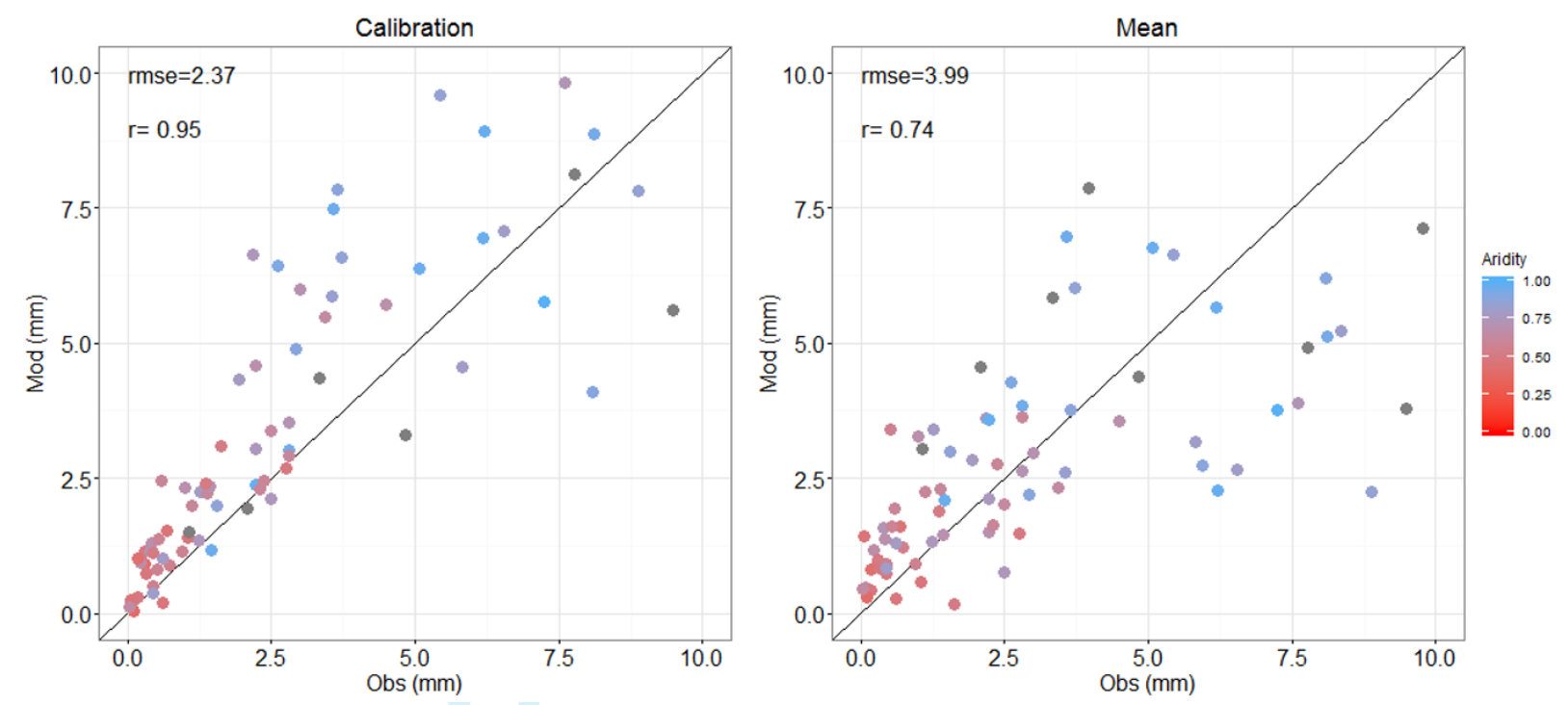

Figure 4. Comparison of observed minimum flow $Q_{\min }$, with predictions from the calibrated and meanvalue parameterizations for Australian catchments. Note that the plot window excludes between 12 and 16 catchments with high values of $Q_{\min }$. rmse=root mean square error in $\mathrm{mm} / \mathrm{mo}$ 

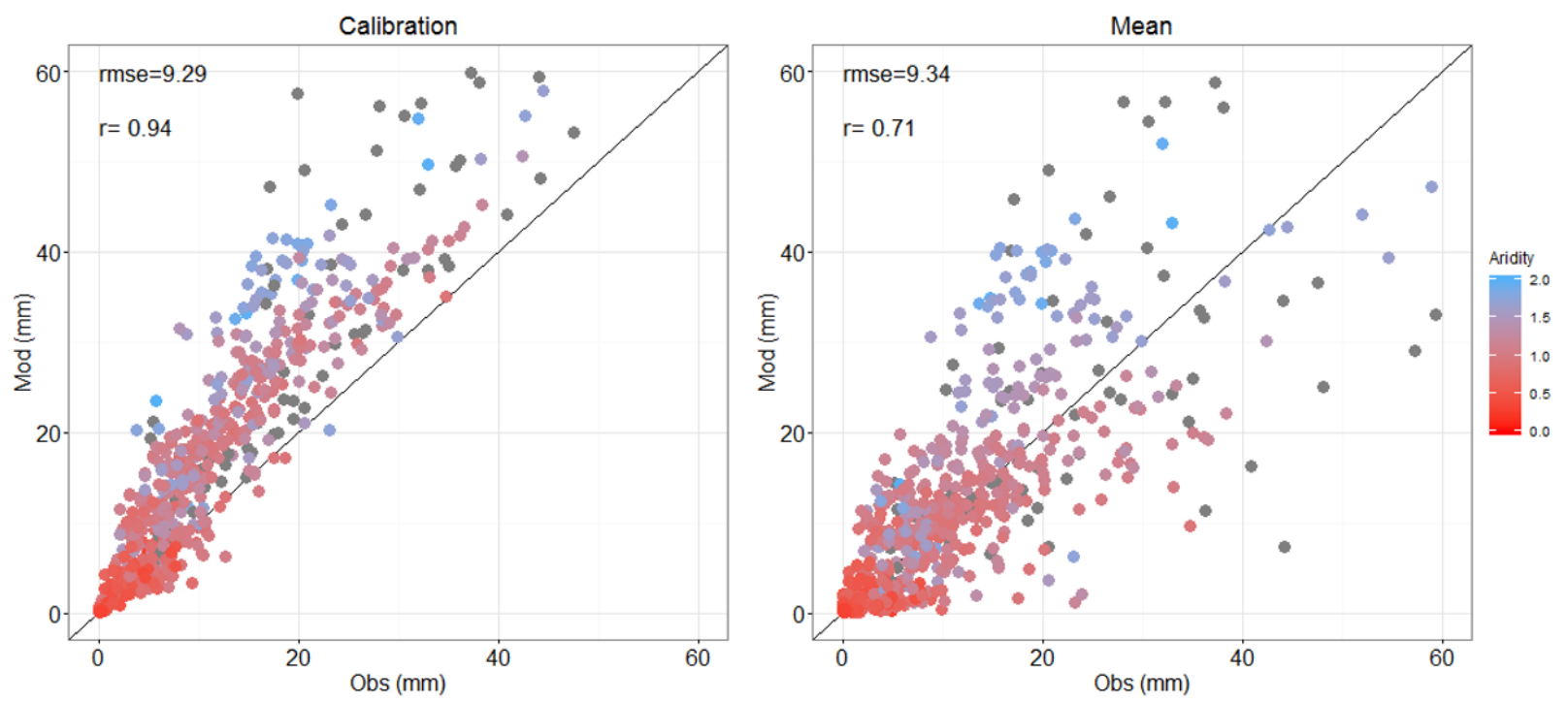

Figure 5. Comparison of observed minimum flow $Q_{\min }$, with predictions from the calibrated and meanvalue parameterizations for US catchments. Note that the plot window excludes between 12 and 16 catchments with high values of $Q_{\min }$. $r m s e=$ root mean square error in $\mathrm{mm} / \mathrm{mo}$ 


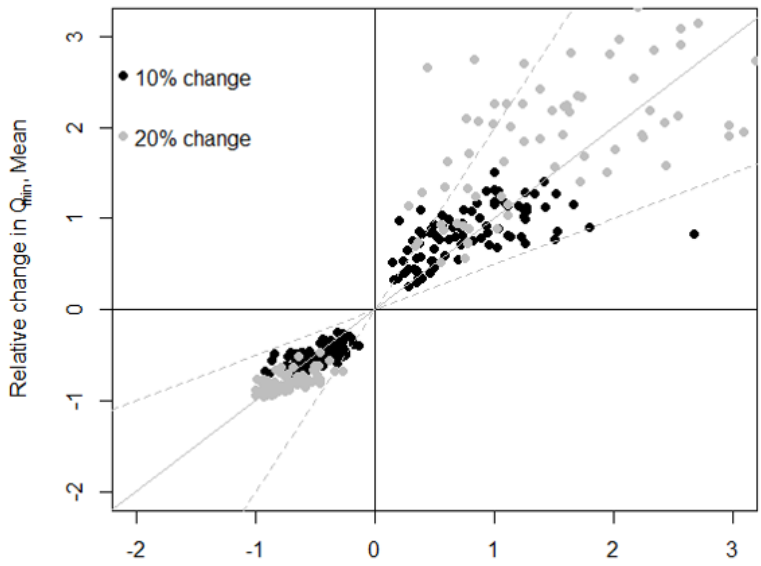

(a)

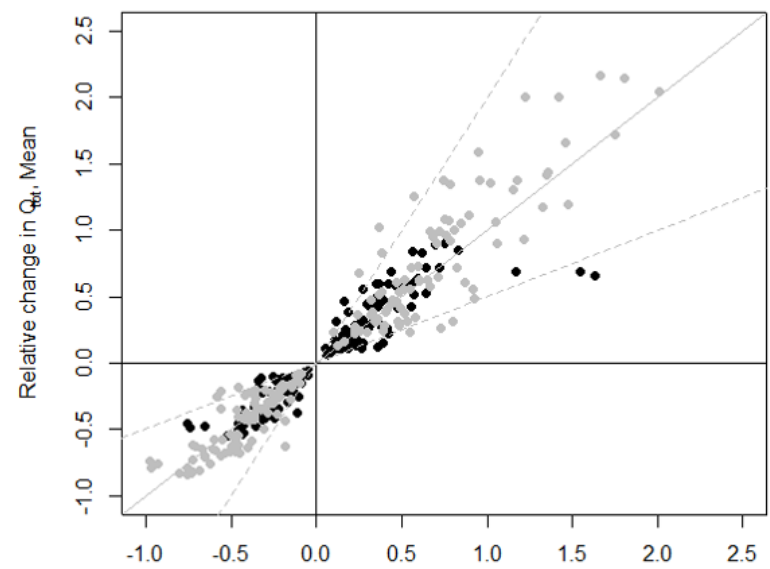

(b)

Relative change in $\mathrm{Q}_{\mathrm{tot}}$, Calibrated

Figure 6. Predictions for $Q_{\min }(a)$ and $Q_{\text {tot }}$ (b) resulting from a hypothetical land use change - i.e. a change in $\alpha_{1}$ and $\alpha_{2}$ values - for both the calibrated and the mean-value models. Each point represents one catchment under either $10 \%$ (black) or $20 \%$ (grey) relative increase or decrease in $\alpha_{1}$ and $\alpha_{2}$. All values in the bottom-left quadrant represent an increase in $\alpha_{1}$ and $\alpha_{2}$, while all values in the top-right quadrant represent a decrease in the two parameters. Dashed lines represent a 50\% difference between the calibrate and mean-value predictions. RMSE for $Q_{\min }$ is 0.36 for the " $10 \%$ change" and 1.2 for " $20 \%$ change". For the increase in $\alpha_{1}$ and $\alpha_{2}$ (bottom-left quadrant), representing afforestation, RMSE for "20\% change" is 0.13 . 
Hydrological Processes

Page 52 of 52

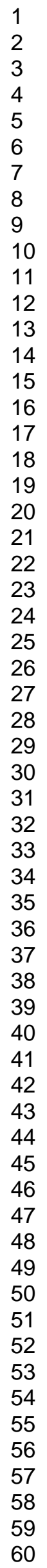
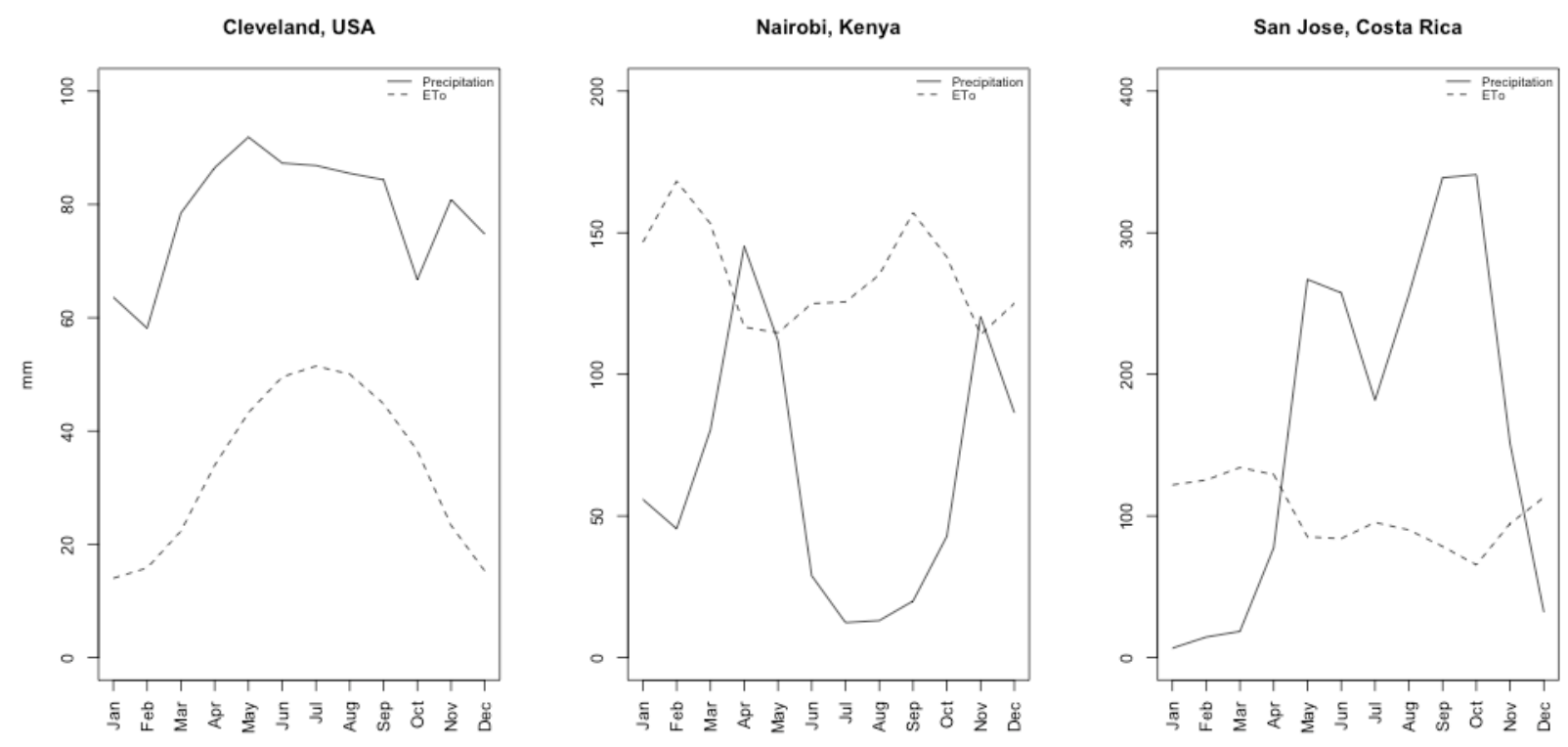

Figure A1. Climate types used in this study: humid continental (Cleveland), subtropical with dry-summer (Nairobi), tropical with dry-winter (San Jose)

http://mc.manuscriptcentral.com/hyp 